\title{
ALBA Y GRUPO DE PUEBLA: LA "VERDADERA" INTEGRACIÓN LATINOAMERICANA O UNA REPETIDA FANTASÍA COLECTIVA
}

\section{ALBA AND GRUPO DE PUEBLA: "TRUe” LATIN AMERICA INTEGRATION OR A REPEATED COLLECTIVE FANTASY}

Marcelo Halperin

\section{RESUMEN}

En este documento se revisa una iniciativa de integración económica (ALBA) desplegada desde comienzos del siglo XXI en América Latina. Este proyecto fue promovido como la mejor opción ("verdadera" integración) a modo de réplica frente a otros formatos adaptados al proceso de internacionalización de los mercados internos. Considerando que dicha internacionalización de mercados constituía ya por entonces una imposición propia de una fase expansiva del sistema económico internacional, el principal problema que afrontaron los impulsores del ALBA fue de naturaleza ideológica: cómo seducir.

Por lo tanto, el autor entiende que el ALBA debe ser objeto de apreciación ya no por sus logros funcionales -que por otro lado son imperceptibles- sino por la influencia ejercida por su narrativa destinada a diferentes sectores de la opinión pública latinoamericana.

El discurso identificado con el ALBA se sustenta en dos guías argumentales. Por un lado, lucen las construcciones mitológicas sobre culturas ancestrales precolombinas y el ensalzamiento de gestas libertadoras que condujeron a la independencia política de los Estados de la región en el siglo XIX. Por el otro, se refuerzan imágenes y símbolos evocadores de un enemigo externo dotado de poderes omnímodos: el capitalismo imperialista.

Una vez agotados los recursos financieros que hacían posible la difusión de su narrativa, el formato ALBA tendió a ser sustituido en la práctica por un foro en cuyo marco se reagruparon sus fundadores: el Grupo de Puebla. A partir de esta instancia las propuestas de integración pasaron a segundo plano, desplazadas por los llamados a conquistar o preservar -según cada caso- el poder político de los líderes presuntamente progresistas y cuyos mensajes continúan inspirando las mismas reivindicaciones y construcciones retóricas.

\section{PALABRAS CLAVE}

Alternativa Bolivariana para los Pueblos de Nuestra América (ALBA), Grupo de Puebla, Tratados de Libre Comercio, guerra jurídica

\section{ABSTRACT}

This paper reviews an economic integration initiative (ALBA) deployed during the early 21 st. century in Latin América. This initiative was promoted as the best option ("true integration") in opposition to the process of internationalization of domestic markets. Taking into account that this internationalization of markets is an imposition proper to the expansion phase of the international economic system, ALBA's main problem was ideological: how to seduce. 
Therefore, ALBA should be appreciated not for its functional achievements -which are unnoticed-but for the influence of its narrative aimed at different sectors of Latin American public opinion.

The speech at ALBA is supported by two discursive guidelines. The first is the appeal to a mythological reconstruction related to ancestral indigenous cultures and the struggles for political independence. As a second plot support, the images and symbols of an all-powerful external enemy are shaken: imperialist capitalism.

Without the resources to finance this narrative, the ALBA format is practically replaced by the Puebla Group. Then the integration proposals go to the background displaced by the calls for the conquest or maintenance -depending on the case- of political power by the presumably progressive leaders who inspire that same preaching.

\section{KEYWORDS}

Bolivarian Alternative for the Peoples of Our America, (ALBA), Puebla Group, Free Trade Agreements, Lawfare 


\section{INTRODUCCIÓN}

La primera cuestión a considerar es la del surgimiento en la región, a principios del siglo XXI, de un proyecto político reivindicativo de la integración económica clara y rotundamente contrapuesto a la internacionalización de los mercados internos impuesta en esta fase de maduración del modo de producción capitalista.

La iniciativa contestataria se difundió mediante sucesivas convocatorias de los Jefes de Estado involucrados en ella. Al cabo de un tiempo y, aunque agotados los que podrían haber sido sus motivos fundacionales, parece útil examinar los principales focos de atención que se desprenden de dicha narrativa: la caracterización de la entidad política intergubernamental que se propuso y todavía se propone construir, como así también los términos de confrontación para perseverar frente a poderes externos supuestamente omnímodos.

Al encarar semejantes desafíos, los promotores de este proyecto reivindicativo debieron plantarse frente a un contexto adverso dentro de la misma región que ya reproducía nítidamente las nuevas condiciones de producción prevalecientes a escala mundial. Entonces debieron valerse de recursos teóricos dotados de la suficiente fuerza de seducción como para contrapesar el pensamiento instalado. La extraordinaria difusión de dicha estrategia persuasiva y su cotejo con los acuerdos intergubernamentales que se fueron gestando invitan al análisis de estos núcleos discursivos.

Con respecto a los fundamentos imputados a la entidad política intergubernamental que daría un carácter distintivo al formato designado como "Alternativa Bolivariana para las Américas" (ALBA), en pugna con un sistema económico internacional catalogado como "capitalismo imperialista", se intentará ponderar su consistencia cotejando dichos fundamentos con los instrumentos de política económica y comercial efectivamente diseñados para las acciones de complementación y cooperación entre los Estados Miembros.

Asimismo, convendrá examinar con mayor detalle las narrativas épicas a través de las cuales se han erigido como mitologías al acervo indigenista y a las gestas por la independencia política libradas en el siglo XIX. Más allá del principio de realidad que sustenta los relatos, parece relevante indagar sobre su eficacia en tanto recurso 
ideológico para la cohesión interna y para la confrontación planteada desde la misma fundación del ALBA con un enemigo externo presentado como contrafigura.

El próximo paso no puede ser otro que el análisis de los instrumentos dispuestos para ser utilizados en este proyecto de integración económica. Al interpretar el sentido de dichos instrumentos, será inevitable preguntarse por qué, al cabo de tanto tiempo, los únicos resultados mensurables del ALBA son los referidos a distintas acciones de cooperación o contribuciones unilaterales no retribuidas.

Si bien las proclamas e iniciativas bajo las insignias del ALBA parecieron diluirse cuando los gobiernos de Venezuela y Cuba quedaron privados de recursos para la cooperación con los otros Estados Miembros, se ha observado últimamente una renovación de su narrativa en el marco del denominado "Grupo de Puebla". Este foro fue creado con el objetivo inicial de replicar al "Grupo de Lima" instituido para neutralizar las prácticas dictatoriales y la vulneración de los derechos humanos en Venezuela. Pero el mensaje del "Grupo de Puebla" no se circunscribe a la defensa de líderes cuestionados, sino que ha venido desarrollando un hilo argumental cuyo análisis no puede soslayarse en la medida que reformula los fundamentos del ALBA.

Por último, sobre la base de la reivindicación al culto de la Madre Tierra, el ALBA y luego el Grupo de Puebla suman su prédica a los reclamos globales ante la depredación y la contaminación ambiental y los graves impactos sobre las condiciones para la preservación de la especie y de la biodiversidad. En este aspecto cabe una lectura de los textos alusivos para detectar cómo se compatibilizan estas propuestas con la exposición de sus otras iniciativas y exhortaciones políticas.

\section{ApRoXIMACIONES: AmÉRICA LATINA EN EL MUNDO DEL SIGLO XXI}

Más allá de las interpretaciones que puedan ensayarse con respecto a las perspectivas históricas del modo de producción capitalista y los sistemas de dominación que lo preservan a escala mundial, es notorio que al ingresar en el siglo XXI la internacionalización de los mercados internos ${ }^{1}$ se profundizó y aceleró con

\footnotetext{
${ }^{1}$ La frase "internacionalización del mercado interno" ya había sido empleada por Fernando Enrique Cardoso al advertir en la década del setenta la permeabilidad de las economías periféricas: "Este concepto, que expresa la situación de dependencia de los países industrializados de la periferia del sistema capitalista, indica que una parte del sistema económico en el interior de la nación -y no sólo el sector extranjero, sino el conjunto del "sector moderno"- se diferencia del resto del sistema económico, adquiere dinámica propia y subordina los demás sectores a su dinámica (que se rige por normas de capitalización, productividad y
} 
características inéditas. Bajo dichas condiciones, las caudalosas corrientes de innovación tecnológica montadas sobre la acumulación y reproducción del capital han ido sustituyendo bienes, servicios y procesos productivos de manera frenética e intempestiva generando expulsiones y desplazamientos masivos de factores y recursos.

Esta redefinición sin fronteras introduce una inédita volatilidad en circuitos diversos: desde los financieros hasta los ocupacionales. $Y$ las turbulencias caen con particular virulencia sobre los países periféricos, dado su papel pasivo ya no sólo en la formación de precios de los productos primarios donde concentran la oferta exportadora, sino también como receptores de las innovaciones tecnológicas que atraviesan todo el sistema productivo².

De modo que, para las sociedades periféricas la depreciación acelerada y luego la desaparición de actividades económicas asentadas sobre tecnologías residuales, directamente pone en riesgo las condiciones de subsistencia de poblaciones cada vez más numerosas. Entonces los Estados nacionales deben intervenir para minimizar el daño infligido por esas calamidades en sus mercados internos. $Y$ atendiendo a que la misma preservación del sistema económico internacional depende de la demanda de consumidores y usuarios desplegados a escala mundial, la propagación de un decaimiento de esa demanda en sociedades periféricas no suele resultar indiferente.

Pero las intervenciones estatales en países periféricos difícilmente pueden prosperar a través de políticas unilaterales, en especial tratándose de países cuyos recursos fiscales están siendo dramáticamente sobrepasados por la necesidad de afrontar, mediante ayudas masivas y subsidios, aquel persistente desplazamiento de sus factores y recursos.

mercado que se asemejan a las vigentes en las economías centrales)" (1972, p. 126). El mismo Cardoso entonces vinculaba dicho proceso con la marginación de los sectores desplazados al no poder insertarse "en la dinámica del desarrollo fundado sobre las grandes corporaciones" (1972b, p. 55).

2 Este último aspecto fue caracterizado con precisión hace algunas décadas atrás por Francisco C. Sercovich (1974), al considerar como fuentes principales de la dependencia tecnológica a la dispersión espacial de la capacidad productiva y a la concentración de las fuentes generadoras de tecnologías (p. 40). En la misma época, Octavio lanni (1973) vinculó dichas transformaciones en las condiciones de producción con el agotamiento de las políticas económicas que habían prevalecido dentro de la región (pp. 134-135). 
La opción de rigor es la negociación de acuerdos internacionales, en especial con países de mayor desarrollo relativo, con el objeto de administrar, sobre bases de reciprocidad, los efectos adversos de la dinámica global sobre las estructuras productivas. Sin embargo, y como consecuencia de las mencionadas intervenciones para compensar la desarticulación de sectores vulnerables cada vez más numerosos, los Estados nacionales en la periferia tienen crecientes dificultades de competitividad para concertar y asumir los referidos compromisos internacionales, en especial cuando no pueden afrontar los riesgos inherentes a las reconversiones sectoriales que imponen las circunstancias ${ }^{3}$.

Así podría explicarse sucintamente por qué, ya entrado el siglo XXI, distintos gobiernos latinoamericanos exacerbaron su reticencia para encarar mediante políticas de concertación internacional su necesaria reconversión productiva. Es en este marco donde han recrudecido con mayor intensidad las narrativas que abogan por una "verdadera" integración regional, esto es, una integración entre países empeñados en obstaculizar la internacionalización de sus mercados internos.

Los gobiernos de países periféricos acosados por sus dificultades para remontar el desafío de la economía global intentan contrarrestar la incertidumbre de sus poblaciones paralizadas por necesidades apremiantes y presas de la incertidumbre. Así, aplican "formas narrativas" tal como las caracterizó Jean-Francois Lyotard: aptas para construir y recrear lazos sociales, implicando la instalación de una previsibilidad (presunción de estabilidad) que sostenga al relato y cumpliendo funciones de legitimación para el orden propuesto a través del mismo relato (1991).

\footnotetext{
${ }^{3}$ Dichas reconversiones en principio no conducen necesariamente a una exacerbación de las economías extractivas o primarias, como suelen denunciar muchos analistas embebidos en un supuesto progresismo. En cambio, los tratados de libre comercio de última generación pueden ser utilizados para propiciar el ingreso a cadenas globales de valor (en tal sentido se debe apreciar la función de política económica que cumplen los requisitos específicos para la calificación del origen de los bienes negociados). Sin embargo, ha de reconocerse que esta inserción en las cadenas globales de valor tiene que lidiar en los países periféricos, tal como se puntualiza en el texto, no sólo con la obsolescencia tecnológica de sus aparatos productivos sino con problemas de competitividad sistémica vinculados al descalabro de las cuentas públicas, en especial por la magnitud de las ayudas sociales y subsidios compensatorios a un creciente número de sectores relegados. Con respecto a la posibilidad de un mejor aprovechamiento de los referidos tratados de libre comercio y su incidencia sobre la competitividad relativa de países en desarrollo", véase Halperin (2021): Los tratados de libre comercio de última generación y su incidencia sobre la competitividad relativa de países en desarrollo. Informe Integrar, (129).
} 
Semejante propuesta tiene escasos puntos en común con la iniciativa desarrollada en los años setenta y plasmada como Grupo Andino y luego como Comunidad Andina de Naciones, en la medida que ésta última, si bien se asimilaba a un programa contestatario, estaba inspirada por el modelo (y también por el discurso) de la comunidad europea ${ }^{4}$.

Durante la primera década del siglo XXI, algunos gobiernos latinoamericanos coincidieron en el trazado de una épica tomando como referencia inicial para su confrontación el cuestionado proyecto del gobierno norteamericano mediante el cual se intentó implantar un "Acuerdo de Libre Comercio de las Américas" (ALCA $)^{5}$. Para

${ }^{4}$ El Acuerdo de Cartagena. firmado el 26 de mayo de 1969. involucró a Bolivia, Chile, Colombia, Ecuador y Perú. Venezuela, que había figurado en las actividades preparatorias a título de observador, adhirió en 1973 y Chile acordó su retiro en 1976. Estas fechas resultan significativas porque marcaron la formación académica de una generación de intelectuales latinoamericanos y no sólo de los países involucrados en la iniciativa. El Acuerdo de Cartagena pasó a ser, rápidamente, objeto de culto. Representó una especie de apuesta política de aquel grupo de países "de desarrollo intermedio" para expandir y acelerar en sus relaciones recíprocas el proceso de integración económica encuadrado en ALALC. Pero las ambiciones no quedaron supeditadas a los temas de la liberalización comercial y a la pretensión de fijar un arancel externo común en el marco andino. El Acuerdo de Cartagena fue sinónimo de una estrategia de desarrollo compartido sobre la base de programas sectoriales de desarrollo industrial junto a la adopción de un régimen común para el tratamiento de los capitales extranjeros, a la transferencia de tecnología y propiedad industrial. $Y$ no fueron metas programáticas, sino la regulación puntillosa de un programa cuya operatividad estuvo respaldada institucionalmente, bajo la inspiración del ejemplo europeo. Se incluyeron dosis nada desdeñables de supranacionalidad, en cabeza tanto del órgano comunitario (la Junta) como mediante la consagración del Tribunal de Justicia, quedando en este caso asegurada la cohesión comunitaria mediante el control de legalidad y el régimen de pronunciamientos prejudiciales para fijar interpretaciones jurídicas uniformes. Vista desde aquellas cumbres fundacionales, la historia de la Comunidad Andina podría ser enfocada como un proceso de progresiva degradación de sus objetivos ante las crecientes dificultades en la implementación de programas conjuntos que implicaran asignación de factores y recursos para un desarrollo compartido.

${ }^{5}$ Las descalificaciones generalizadas sobre esta iniciativa no deberían impedir una evaluación sobre los esfuerzos realizados por las cancillerías de numerosos países latinoamericanos para diseñar mecanismos que permitieran la extensión y profundización de las concesiones subregionales en el curso de las mismas negociaciones hemisféricas abiertas por la IV Reunión Ministerial de Comercio en San José de Costa Rica (19 de marzo de 1998). Ya en ese cónclave fue planteada con claridad la necesidad de preservar en el seno del ALCA los acuerdos subregionales entre países latinoamericanos. Si bien finalmente el proyecto ALCA quedó de hecho sepultado en la IV Cumbre de las Américas (Mar del Plata 2004), el acopio de datos, los estudios de factibilidad y debates generados hasta entonces en la región contribuyeron para encauzar la negociación de distintos acuerdos de libre comercio de última generación por países miembros de la Asociación Latinoamericana de Integración (ALADI). Así, por ejemplo, en el seno de la ALADI y al impulso del economista Leonardo Mejía (entonces secretario general adjunto), fue analizado el desempeño y las perspectivas de los países de 
sostener sus proposiciones alternativas al ALCA estos gobiernos latinoamericanos, encabezados por el de Venezuela, pergeñaron un formato bautizado como "Alternativa Bolivariana para las Américas" o bien "Alternativa Bolivariana para los Pueblos de nuestra América" (ALBA), valiéndose de recursos que les aportó el incremento de los precios internacionales de los hidrocarburos que constituyen su principal oferta exportable ${ }^{6}$. Así ganaron la adhesión de países de la región caracterizados por ser importadores netos de combustibles ${ }^{7}$. Simultáneamente solventaron campañas de seducción colectiva en los medios de prensa y en las estructuras educativas que se difundieron en toda la región.

Transcurrida una década y más allá del recambio de gobiernos y la pérdida de las fuentes de financiamiento que pudieran respaldar la propagación de esa narrativa, el mismo hálito seductor sigue latiendo en diversos ámbitos. De ahí que numerosos líderes políticos latinoamericanos, bajo diversas coyunturas estén dispuestos a revitalizar dicha construcción discursiva con el objeto de captar el apoyo de poblaciones acosadas por las turbulencias que sacuden con creciente intensidad al sistema económico internacional.

En esta línea, quienes pretenden manipular la opinión pública se preguntan: ¿cuáles serían los argumentos con visos de mayor credibilidad para dotar a las creencias colectivas de argumentaciones contestatarias, pero a la vez confortables y llevaderas? Al respecto aquí se presentan algunas hipótesis básicas procurando develar el sentido

menor desarrollo económico relativo de la Asociación, esto es, Bolivia, Ecuador y Paraguay, frente a los desafíos que representaba el ALCA en tanto reconfiguración de concesiones y preferencias comerciales entonces vigentes. Véase, por ejemplo, Da Mota Veiga y Halperin (2001): Definición de una estrategia para la preservación de las preferencias intra-ALADI en el acuerdo que establecería el ALCA.

6 "Venezuela organizó el ALBA en un formato eje-rayos que aseguró la dependencia de sus miembros de los recursos del gobierno venezolano" (Giacalone, 2021, pp. 31-32). Para un análisis de la política interna venezolana y su reflejo sobre las iniciativas de integración véase: Schaposnik y Pardo (2016).

7 En primer lugar, habría que considerar a los países caribeños, demandantes de hidrocarburos. Sin embargo, en algunos casos la incorporación al ALBA como Partes, desde el punto de vista formal resultó ficticia, porque como se reconoció en el Acuerdo para la constitución del Espacio Económico del ALBA-TCP: "Dado que Antigua y Barbuda, la Mancomunidad de Dominica y San Vicente y las Granadinas son miembros de la Unión Monetaria del Caribe Oriental (UMCO), de la Unión Económica de la OECO y de la CARICOM se hace necesario que el ALBA TCP inicie conversaciones con la UMCO, la OECO y la CARICOM sobre los temas tratados en el presente Acuerdo, especialmente el SUCRE y los acuerdos arancelarios asociados al comercio" (2012, artículo 15). 
que campea en la difusión de concepciones y slogans con motivo de una hipotética y "verdadera integración" (regional o sub-regional según sea el caso) ${ }^{8}$.

\section{LOS ELEMENTOS NARRATIVOS DE UNA ÉPICA}

La coincidente reaparición y consolidación de gobiernos genéricamente catalogados como "populistas" en distintos países latinoamericanos a comienzos del siglo XXI generó un revuelo político encauzado institucionalmente mediante acuerdos y organismos regionales y sub-regionales. Así se suscribieron: la citada Alternativa Bolivariana para los Pueblos de Nuestra América (ALBA) en 20049; el Tratado Constitutivo de la Unión de Naciones Suramericanas (UNASUR) en 2008 ${ }^{10}$; y la Comunidad de Estados Latinoamericanos y Caribeños (CELAC) en $2011^{11}$.

\footnotetext{
${ }^{8}$ Para instalar la categoría lógica de "verdad" en un proceso de integración, la Declaración Conjunta suscrita por los Presidentes Hugo Chávez Frías de la República Bolivariana de Venezuela y Fidel Castro de Cuba, dada en La Habana el 14 de diciembre de 2004, sostiene: "...que la Alternativa Bolivariana para las Américas (ALBA) propuesta por el Presidente Hugo Chávez Frías en ocasión de la III Cumbre de Jefes de Estado y de Gobierno de la Asociación de Estados del Caribe, celebrada en la isla de Margarita en diciembre del 2001, traza los principios rectores de la verdadera integración latinoamericana y caribeña, basada en la justicia, y nos comprometemos a luchar conjuntamente para hacerla realidad" (párr. 7).

9 Inicialmente "Alternativa Bolivariana para los Pueblos de Nuestra América" (ALBA) en 2004. En la Cumbre Extraordinaria de Maracay, Venezuela, el 24 de junio de 2009 los Jefes de Estado y de Gobierno "decidieron que a partir de esta VI Cumbre, el ALBA-TCP se denominará "Alianza Bolivariana para los Pueblos de Nuestra América-Tratado de Comercio de los Pueblos" (ALBA-TCP), en el entendido que el crecimiento y fortalecimiento político del ALBATCP la constituye en una fuerza real y efectiva" (párr. 6). A este formato propulsado por Venezuela y Cuba, luego se fueron incorporando Bolivia, Nicaragua, Ecuador, San Vicente y las Granadinas, Antigua y Barbuda, Dominica, Granada, San Cristóbal y Nieves, Surinam y Santa Lucía. Debido a los cambios en la orientación política de los gobiernos, se retiraron Ecuador y Bolivia. Y al revertirse nuevamente su orientación política, el "Estado Plurinacional de Bolivia" reingresó al esquema y ese regreso fue celebrado en ocasión de la XVIII Cumbre realizada el 14 de diciembre de 2020.

10 El Tratado Constitutivo de la Unión de Naciones Suramericanas (UNASUR) firmado en Brasilia el 23 de mayo de 2008, entró en vigor al ratificarlo el noveno país suscriptor, según lo previsto, el 11 de marzo de 2011. La parábola institucional de la UNASUR exhibe una llamativa conflictividad. En un relevamiento de abril de 2018 se constató que ya habían suspendido su membresía Argentina, Brasil, Chile, Colombia, Paraguay y Perú. Luego fueron formalizadas las denuncias del Tratado durante ese año y el siguiente. Cuando el canciller de Uruguay anunció que su país se retiraba del organismo, el 10 de marzo de 2020, indicó que había sido abandonado por la mayoría de los países de la región, a excepción de Guyana, Surinam y Venezuela. El comunicado de prensa (número 18/2020 del MRREE) expresaba entonces: "...se trata de un organismo regional, basado en alineamientos político-ideológicos y que, en los hechos, ha dejado de funcionar: ya no cuenta con sede y carece de Secretaría General operativa" (2020, parr. 2).

${ }^{11}$ Las Jefas y los Jefes de Estado y de Gobierno de los treinta y tres países de América Latina y el Caribe reunidos en Caracas los días 2 y 3 de diciembre de 2011, al cabo del encuentro emitieron una Declaración ("Declaración de Caracas") poniendo en marcha la denominada "Comunidad de Estados Latinoamericanos y Caribeños" (CELAC). Sus antecedentes
} 
Tanto la UNASUR como la CELAC fueron concebidos ante todo como marcos de cooperación y no como instrumentos para las transacciones comerciales o económicas, de modo que el peso asignado al desarrollo de una "verdadera" integración económica se focalizó en el ALBA ${ }^{12}$.

Tomando como eje no sólo las referencias textuales de todos estos instrumentos, sino en especial examinando los mensajes intercambiados por los líderes gubernamentales en ocasión de las Cumbres del ALBA, es posible deletrear una narrativa elaborada simultáneamente con vistas a la irrupción en los claustros y a expandirse hasta el punto de incidir en la opinión pública con respecto a cuestiones ajenas al proceso de integración en sí.

Aunque resulta difícil medir su grado de penetración, es notoria la persistencia de dicha orientación discursiva incluso en los períodos signados por el ulterior cambio de orientación de los gobiernos cuyos países habían participado activamente en la instalación de esa misma narrativa. Tal persistencia invita a examinar su estructura discursiva con el objeto de poner al descubierto los mecanismos de seducción que la caracterizan.

En una primera aproximación a esa estructura, parecería que para ganar credibilidad sobre la "verdadera integración" deberían satisfacerse dos objetivos perentorios y necesariamente articulados: definir la entidad política y económica del colectivo intergubernamental y, simultáneamente, las marcas de identidad reflejadas por la confrontación con un $\mathrm{amo}^{13}$.

inmediatos fueron aportados por dos "Cumbres de América Latina y el Caribe" (CALC). La primera de ellas se celebró el 17 de diciembre de 2008 en San Salvador de Bahía y la segunda en Cancún el 23 de febrero de 2010. En los foros de la CELAC cundió la iniciativa de hacer del organismo una OEA propiamente latinoamericana y caribeña. Así lo expresó literalmente el presidente ecuatoriano Rafael Correa durante la IV Cumbre celebrada en Quito durante el mes de enero de 2016: "necesitamos un organismo latinoamericano y caribeño capaz de defender los intereses soberanos de sus Miembros. La OEA nos alejó de ese propósito reiteradamente" (Paz y Cepeda, 2016, párr. 10).

${ }^{12}$ Sin desmedro de las numerosas acciones de cooperación diseñadas también en el ALBA, según se describen más abajo.

13 Discurriendo acerca del problema de la identidad en el marco de la integración cultural, Waldo Ansaldi cita a Lamo de Espinosa para señalar que es en el enfrentamiento donde se gesta la identidad propia y la ajena. Así: "es el otro quien me otorga/niega reconocimiento y es a través de su mirada como me formo un "yo". Yo sólo lo soy para otro, y viceversa, como en un juego de espejos. Dicho de otra manera: la identidad se define por y a través de la oposición, es decir, del conflicto" (Lamo de Espinosa como citado en Ansaldi, 1997, p. 67). 
A propósito de esta concurrencia de objetivos, convendría interpretar al ALBA según el registro hegeliano. En efecto, aquí se trata de perfilar una identidad -La Patria Grande14 frente a su "no reconocimiento" por el amo: capitalismo, imperialismo, empresas transnacionales.

No habría que esperar del amo reconocimiento alguno. Pero, por otro lado, ¿acaso la propuesta para una "verdadera integración" no constituye, al erigirse como tal, en un reconocimiento del amo? Si así fuera, cabría suponer que para los adalides de la "verdadera integración" la batalla no habría sido dada y, como en el caso del esclavo en la teoría hegeliana, el reconocimiento al amo debería entenderse como contrapartida de una renuncia o cesión frente al riesgo de perderlo todo (precisamente, se habría renunciado a la lucha en aras de obtener el reconocimiento). Entonces la "verdadera integración" tendría que aspirar a meros paliativos. Sin embargo, como se verá más adelante, su narrativa es beligerante: la lucha con el capitalismo imperialista y las empresas transnacionales todavía estaría pendiente ${ }^{15}$.

\section{III.1. El primer objetivo: delinear la nueva entidad política y económica}

Ante todo, se trata de simplificar al extremo las razones sistémicas de la desigualdad económica y social al interior de cada uno de los países involucrados y entre los países que suscribirían el proyecto de integración. El mismo proyecto facilita este objetivo porque amplía el foco ("la patria grande") y sobre la base de una pertenencia compartida presume que las disparidades e insuficiencias pueden afrontarse con éxito a través de acciones altruistas. En este aspecto se utiliza reiteradamente la voz "solidaridad" aunque sin reminiscencias sociológicas ${ }^{16} \mathrm{y}$, en cambio, asignándole

\footnotetext{
${ }^{14}$ La expresión "Patria Grande" para referirse a América Latina fue instalada por Manuel Ugarte en su libro que precisamente tituló "La Patria Grande" (1922). Las ideas de este polemista y viajero argentino fueron tan reconocidas como cuestionadas durante la primera mitad del siglo XX. Para repasar su elogio del mestizaje y algunas de las implicaciones más controvertidas de sus posturas anti-imperialistas, véase el estudio de Pasquaré (2014) Exilio y patria en Manuel Ugarte: su campaña continental de 1911-1916.

${ }^{15}$ Véase una síntesis ilustrativa de los referidos términos teóricos hegelianos en Kojeve (1982, p. 16).

${ }^{16}$ Se debe a E. Durkheim (1967) el desarrollo de una teoría sociológica sobre el sistema de división del trabajo social en los países capitalistas inmersos en la segunda revolución industrial. Precisamente para explicar la división del trabajo social este gran maestro de la sociología clásica recurre a una tipología que amalgama la dimensión de pertenencia (solidaridad "mecánica") con otra dimensión, superpuesta a la anterior, que hace posible la división del trabajo social (solidaridad "orgánica"). Pero a la conceptualización "objetiva" de la solidaridad propuesta por Durkheim como sustento de la cohesión social, se le contrapuso una noción "subjetiva" que terminó absorbiendo y entonces acaparando el significado del término.
} 
sentido subjetivo de "buena voluntad" para reconocer insuficiencias y disparidades estructurales y conceder un trato especial y diferenciado destinado a contrarrestarlas.

Sobre la base de las pertenencias imputadas a los acervos de las culturas indígenas ancestrales y al mandato imputado a los Padres Fundadores de las naciones latinoamericanas en el siglo XIX, los adalides de la "verdadera integración" se presentaron como impulsores de instrumentos de concertación internacional de acciones de complementación y cooperación cuyas prestaciones y contra-prestaciones responderían a la solidaridad entre las Partes y no a las vilezas (capitalismo, imperialismo) atribuidas al sistema económico internacional prevaleciente. Este contraste fue remarcándose con llamativa ingenuidad y quedó plasmado al instituirse los proyectos y empresas gran-nacionales en la Sexta Cumbre del ALBA-TCP (2008):

El concepto de empresas gran nacionales surge en oposición al de las empresas transnacionales, por tanto, su dinámica económica se orientará a privilegiar la producción de bienes y servicios para la satisfacción de las necesidades humanas garantizando su continuidad y rompiendo con la lógica de la reproducción y acumulación del capital (párr. 21) (...) La producción final de estas empresas debe destinarse prioritariamente a satisfacer el consumo final o industrial del mercado intra-alba, a objeto de conformar la zona de comercio justo. Sus excedentes podrán colocarse en el mercado internacional (párr.26) (...) Con respecto a la modalidad de estas empresas, (ellas) pueden ser binacionales, con una composición accionaria que garantice la soberanía de cada país. En el caso de las empresas gran nacionales entre varios o todos los Estados Miembros, los aportes se harán de acuerdo a las posibilidades de cada Parte. Las decisiones se tomarán siempre por consenso y los márgenes

Según Harry Alpert (1945): “...el concepto fundamental empleado por Durkheim (...) fue el de SOLIDARITÉ. Este término ha sido traducido sin titubeo alguno en los países de lengua inglesa con la palabra SOLIDARITY (...) Pero quisiéramos advertir, sin embargo, que estos términos, aunque afines, no son exactamente equivalentes. El término inglés, por lo menos en su uso corriente, tiene una connotación moral y valorativa más acentuada que la poseída por el vocablo francés en los días de su empleo por Durkheim. Este empleaba la palabra SOLIDARITÉ, en un sentido objetivo y hasta biológico, para indicar un determinado tipo de relación entre un todo y sus partes. Más al cabo de pocos años de aparecer el trabajo de Durkheim, León Bourgeois publicó un pequeño volumen titulado "La Solidarité" donde se sentaban los principios de un movimiento moral y político que vino a ser conocido con el nombre de solidarismo (...) El término adquirió en consecuencia un marcado tono moral..." (p. 216). 
económicos que se obtengan se destinarán al crecimiento de la propia empresa y/o al desarrollo de proyectos de carácter social (párr. 32) ${ }^{17}$.

Aquí aparecen en primer plano los postulados de la "verdadera integración" reflejados a través de la actividad empresarial: romper con la lógica de la reproducción y acumulación del capital; y, en contraposición, emprender un comercio justo, aportes de acuerdo a las posibilidades de cada Parte y decisiones por consenso.

Las enunciaciones precedentes deben analizarse considerando que no sólo constituyen una caracterización "ideológica" de objetivos, sino que denotan una interpretación del sistema económico internacional tal como estaría estructurado, en tanto los mentores del ALBA postulan la viabilidad de la ruptura "lógica" de la acumulación y reproducción del capital para implantar en su lugar otra lógica susceptible de ser aplicada a las relaciones comerciales e inversiones intergubernamentales. Dentro de esta lógica sustitutiva pasaría a un segundo plano la hipótesis de controversia o conflicto de intereses en tanto dichas relaciones comerciales e inversiones intergubernamentales sólo podrían tener lugar habiendo intereses convergentes. A partir de la IX Cumbre este supuesto de convergencia se identifica con el socialismo:

Los Jefes de Estado y de Gobiernos de Antigua y Barbuda, Bolivia, Cuba, Dominica, Ecuador, Nicaragua, San Vicente y Las Granadinas y Venezuela, países miembros de la Alianza Bolivariana para los Pueblos de Nuestra América-Tratado de Comercio de los Pueblos (ALBA-TCP), al conmemorar hoy 19 de abril el Bicentenario del inicio de la lucha por la Independencia venezolana, ratificamos nuestro compromiso con la tarea de consolidar la soberanía de nuestros pueblos y construir el camino hacia el socialismo (párr. $2)^{18}$.

\footnotetext{
17 Párrafos extraídos del documento "Conceptualización de proyecto y empresa gran nacional en el marco del ALBA", emitido por la Sexta Cumbre de Caracas, 26 de enero de 2008. La imposibilidad de traducir esta propuesta como un instrumento apto para la integración económica, dio lugar a que -como se puntualiza más adelante- en febrero de 2012 la IX Cumbre previera un calendario de aproximaciones progresivas (Acuerdo para la constitución del Espacio Económico del ALBA-TCP, artículo 8).

18 Manifiesto Bicentenario de Caracas. Declaración Final de la IX Cumbre del ALBA. Teatro Teresa Carreño, 19 de abril de 2010.
} 
Este último enunciado es apenas retórico, pues ni antes ni después de la IX Cumbre se adoptaron decisiones encaminadas hacia alguna forma de socialismo compartido. Entonces sólo queda en pie aquella pretensión de "romper con la lógica" de la economía capitalista mediante un diseño apoyado en el voluntarismo a cargo de cada Parte y en todo momento.

Por lo tanto, a esta altura el analista debe preguntarse por la fuente de inspiración a la que habrían recurrido los adalides de la "nueva integración" para postular un formato de integración económica sobre los fundamentos indicados. Si bien resulta difícil encontrar una respuesta fidedigna, algunos de sus principios remiten, inequívocamente, a las tradiciones de la denominada "economía social" practicada e institucionalizada en Europa durante el siglo XIX para encuadrar las actividades de cooperativas, mutuales y asociaciones sin fines de lucro ${ }^{19}$. En especial:

(i) Sustituir la búsqueda del lucro por la de prestaciones solidarias y destinadas a fines sociales; $y$

(ii) Adoptar procedimientos decisorios democráticos, que en el caso de la "verdadera integración" se manifiestan por el consenso (en tanto dentro del sector privado esta fórmula suele consistir en la asignación uniforme de votos y, en general, reconociendo a cada sujeto un voto).

De todos modos, el modelo de una "economía social" subyacente y que inspira la iniciativa del ALBA está en las antípodas de la construcción más destacada que se ha formulado como expresión del pensamiento utópico y filo-socialista en la historia latinoamericana: el proyecto de Simón Rodríguez, insigne maestro y amigo de Bolívar.

\footnotetext{
19 "En los años setenta, al calor de la crisis y del consiguiente fenómeno de reconocimiento mutuo y de solidaridad de varios movimientos socioeconómicos franceses, el cooperativo, el mutualista y el asociativo, re-emerge el concepto de economía social. Su campo se extiende a todas aquellas formas que en su funcionamiento contestan y cuestionan la lógica del desarrollo capitalista" (Chaves y Monzón, 2003, pp. 187-188). En paralelo es difundida la modalidad del "comercio justo" instalada por asociaciones de beneficencia tras la segunda guerra mundial y que a través de la certificación de productos involucra incluso a corporaciones transnacionales. Recientemente se ha procurado examinar el "comercio justo" articulando desde el punto de vista teórico el tratamiento de las inequidades "de libre mercado" tanto en el orden interno de cada país como en el sistema económico internacional. Sobre este aspecto son destacables las reflexiones de Matthías Schmelzer expuestas en su documento "Comercio Justo y Libre Mercado" escrito en 2007 para la Universidad de California, Berkeley.
} 
En tal sentido y, a diferencia de la propuesta de Simón Rodríguez, la "economía social" en el ALBA está circunscripta como materia de acuerdos intergubernamentales y sin prever su internalización y propagación a través del sistema educativo en los estratos sociales sumergidos, tal como lo postulaba Simón Rodríguez. Sintetizando su célebre contribución se ha escrito que:

De ese proceso de colonización interna, no con fines de dominación sino de liberación, hecha con jóvenes educados para el ejercicio de la economía social, nacerían las toparquías (gobierno del territorio, del topos) la forma más perfecta de gobierno que pueda imaginar la mejor política. Comunidades en las que se produce según lo que los tipos de suelo, clima, capacidades de la gente, vías de comunicación, y demás factores de producción que permitan producir con ventajas. Las comunidades estarían articuladas entre sí en confederaciones de toparquías organizadas desde y para el intercambio solidario, supervisadas por un gobierno central planificador (visión bolivariana), creador de normas generales y supervisor de sus ejecuciones, gobierno que a su vez estaría bajo la supervisión de la confederación de toparquías (Romero Alfonzo, 2021, p. 231) 20.

Aunque muy lejos de las aspiraciones de reformulación social que Simón Rodríguez consideró indispensable como punto de partida de una reestructuración económica, de todos modos, las postulaciones del ALBA fueron adquiriendo las retóricas del socialismo. En tal sentido, es posible rastrear el tránsito desde una integración concebida inicialmente como composición de nacionalismos convergentes hacia la integración bajo consignas nominalmente "socialistas". De tal modo, se llega a este punto en que la invocación del socialismo le proporciona al ALBA una carátula más atractiva, pero semejante viraje no resultó de algún debate de ideas, a diferencia de aquella recordada disputa entre Mariátegui y Haya de la Torre en $1928^{21}$.

Sin embargo, la invocación del socialismo resultó, al igual que la del altruismo inicial, apenas una carátula. Entretanto, con motivo del diseño de las políticas comerciales que debían concertarse, hubo que reconocer la persistencia de intereses nacionales contrapuestos y que por lo tanto requerían distintas formas de compatibilización. Tales

${ }^{20}$ La frase en negrita corresponde a la cursiva que utiliza el autor citado, para indicar una referencia textual al escrito de Simón Rodríguez.

${ }^{21}$ Bergel (2021), sintetiza ilustrativamente la evolución del pensamiento de Mariátegui y los lineamientos de la disputa en "El socialismo cosmopolita de José Carlos Mariátegui". 
previsiones están incluidas en un "Acuerdo para la constitución del Espacio Económico del $A L B A-T C P^{\prime 22}$. Así, dentro del mismo texto que reitera las invocaciones al altruismo y la solidaridad, se cuelan algunas previsiones para incorporar, al cabo de dos años de la puesta en vigor de dicho Acuerdo, los mismos instrumentos de política comercial contemplados por los "tratados de libre comercio" paradójicamente vilipendiados, a saber: régimen de origen; normas técnicas; incentivos de promoción y articulación industrial y al intercambio; salvaguardias; medidas sanitarias, fitosanitarias y zoosanitarias; solución de controversias (...) (2012, art. 3) $)^{23}$. Dichas previsiones hubieran debido inspirarse en los acuerdos multilaterales de la Organización Mundial del Comercio (OMC). Pero en tal caso hubieran sido de difícil cumplimiento debido al reconocimiento a las Partes de una amplia discrecionalidad, según previsiones del mismo Acuerdo. Esta contradicción jurídica nunca surgió a la luz porque, sencillamente, dicho Acuerdo quedó reducido a letra muerta.

\section{III.2. El segundo objetivo: confrontar con el Amo}

Denunciando las prácticas de los Estados imperialistas y las corporaciones transnacionales, ${ }^{24}$ a través de la "verdadera" integración se asume discursivamente una posición militante que reivindica dos gestas: las rebeliones indígenas contra la conquista, por un lado; y las guerras revolucionarias del siglo XIX conducentes a la independencia y creación de los estados latinoamericanos, por otro lado.

Más allá de la descontextualización histórica, esta invitación a participar en relatos mitológicos se asienta sobre un principio de realidad que convalida las denuncias: atropellos locales contra pobladores que representan culturas ancestrales; y agresiones internacionales a través de recurrentes políticas y prácticas imperialistas ${ }^{25}$.

\footnotetext{
22 Dado en la undécima Cumbre, Caracas, Venezuela, 4 de febrero de 2012.

${ }^{23}$ Acuerdo para la constitución del Espacio Económico del ALBA-TCP, artículo 3.

${ }^{24}$ Por ejemplo, véase la siguiente declaración de los Jefes de Estado y de Gobierno del ALBA en la Séptima Cumbre, Cochabamba, Bolivia, dada el 17 de octubre de 2009:

"1. Por su esencia, el capitalismo y su máxima expresión el imperialismo, están destruyendo la propia existencia de la humanidad y nuestra Madre Tierra. La crisis económica global, la crisis del cambio climático, la crisis alimentaria, y la crisis energética son de carácter estructural y se deben, fundamentalmente, a patrones de producción, distribución y consumo insostenibles, a la concentración y acumulación del capital en pocas manos, al saqueo permanente e indiscriminado de los recursos naturales, a la mercantilización de la vida y a la especulación a todos los niveles para beneficio de unos pocos" (párr. 5).

${ }^{25}$ El trasfondo imperial del panamericanismo es fácilmente reconocible desde antes, durante y después de la guerra fría. Una reseña de las principales intervenciones norteamericanas bajo el amparo de sus regulaciones y con especial referencia a Cuba, se publicó en EcuRed, la
} 
De ahí que no sea necesario acudir a trazas delirantes para elaborar y difundir semejantes proclamas y lograr alguna credibilidad con ellas.

Pero es preciso señalar que la instalación del enemigo expoliador externo (a veces individualizado como "Estados Unidos de América"; otras veces como "capitalismo imperialista"; o bien como "imperialismo"), limita al ALBA en su punto de partida de manera drástica porque descalifica una eventual interrelación con dicho enemigo. De modo que, concebido en tanto formato de integración económica, el ALBA constituye una expresión beligerante y por lo tanto no encuadra dentro de las previsiones del GATT/OMC para los esquemas ideados con el objeto de profundizar relaciones económicas y comerciales.

En definitiva, el ALBA se sostiene sobre dos postulados inconmovibles, aunque desavenidos: (i) el enemigo "capitalismo-imperialismo" representaría, dado su extraordinario poder, una amenaza destructiva bajo cualquier circunstancia ${ }^{26}$; y (ii) el enemigo aún no habría contaminado totalmente a los mercados internos de los países que concurren al ALBA y, de ahí, la supuesta viabilidad de esta alternativa contestataria de integración económica.

Semejantes postulados, potencialmente contradictorios entre sí, afectan la verosimilitud del proyecto de integración. Así, mal que les pese a los propulsores del ALBA, resulta imposible soslayar dos evidencias. La primera es que la internacionalización de los mercados internos ya era un hecho incontrastable a la época de fundarse el ALBA, lo que implicaba tener que convivir con el enemigo ${ }^{27}$. La segunda evidencia, producto de la anterior, es el surgimiento, sobre la base de dicha globalización, de contradicciones secundarias que atraviesan todo el sistema

enciclopedia colaborativa en red del gobierno de Cuba (www.ecured.cu/OEA), sin fecha y con datos actualizados al 2015.

26 "Desde su nacimiento en el año 2004, en sus conceptos y sus prácticas, el ALBA ha constituido una alternativa a los esquemas de integración neoliberales y fundamentalmente el proyecto económico imperial del ALCA, un espacio de respuesta y protección efectiva ante las crisis energética, financiera, alimentaria y social desencadenadas por el capitalismo globalizado que hoy amenaza la existencia de la Madre Tierra y la supervivencia de la humanidad" (Manifiesto Bicentenario de Caracas. Declaración Final de la IX Cumbre del ALBA, 2010, p. 1).

${ }^{27}$ El cuestionamiento a un anti-imperialismo simplista o reduccionista tiene rica historia en la región. El punto de partida bien puede situarse en el debate entre Carlos Mariátegui y Víctor Haya de la Torre en la Conferencia Comunista Latinoamericana celebrada en Buenos Aires en 1929. Según advierte Funes (2011), fue allí donde Mariátegui, con su ponencia titulada "Punto de Vista Antiimperialista", discutió la perspectiva de Haya de la Torre señalando la debilidad del postulado sostenido por el fundador del aprismo en tanto no contemplaba la necesidad de recurrir a una estrategia para propiciar la convergencia de las clases sociales sometidas. 
económico internacional y que precisamente hacen aún más compulsiva la necesidad de formalizar vínculos intergubernamentales entre países centrales y periféricos. No debe pasarse por alto que en los países centrales (capitalistas, imperialistas) se multiplican los factores de la producción desplazados a una condición periférica en esos mismos territorios (esto es, tecnologías que se deprecian intempestivamente y poblaciones cautivas de dichas tecnologías depreciadas), en tanto los países periféricos están expuestos a factores y recursos irradiados desde países centrales que invaden, lícita o ilícitamente, sus propios mercados e imponen también una depreciación acelerada de las tecnologías en uso con el consiguiente daño a poblaciones también cautivas de ellas. En otros términos: la ecuación centro-periferia no se identifica con los territorios nacionales y, en cambio, caracteriza las contradicciones internas tanto en las sociedades centrales como en las periféricas. $Y$ estas contradicciones se agudizan y profundizan con la aceleración del ritmo impreso a las sustituciones tecnológicas.

Una de las manifestaciones típicas de dicha agudización y profundización de las contradicciones secundaria en el sistema económico internacional es el auge de las tecnologías de la información y las comunicaciones (TIC). La explotación de estas tecnologías se ha encauzado empresarialmente a través de plataformas insertas en la virtualidad, desapegadas de cualquier asentamiento territorial que pudiera comprometer su expansión a través de la manipulación irrestricta de los contenidos intangibles lanzados a los mercados globales. Esta modalidad operativa de las corporaciones transnacionales involucradas en las TIC compromete la integridad fiscal y hasta la cohesión social que se supone resguardada por los Estados nacionales. Operando "en la nube", las corporaciones transnacionales (BIG-TECH) viabilizan la evasión de cargas fiscales y simultáneamente capturan datos de usuarios y consumidores, tanto en los centros como en las periferias, para enhebrar cadenas de valor y desarrollar mecanismos de penetración en los mercados sin que las políticas económicas nacionales puedan siquiera regular los efectos de esta dinámica sobre sus propios residentes ${ }^{28}$.

Los promotores del ALBA no ignoraron estos procesos. En tal sentido, la XI Cumbre realizada en Caracas los días 4 y 5 de febrero de 2012 incluyó una Declaración Final

${ }^{28}$ El autor exploró la cuestión en (2020) La ciudadanía digital en el cielo latinoamericano. Informe Integrar, (124). 
sobre Medios de Comunicación que retomó expresiones vertidas en la VII Cumbre, de octubre de 2009, acerca de la necesidad de construir "un modelo comunicacional que permita un verdadero encuentro con nuestros pueblos, fortalezca los procesos democráticos en la región y rompa el cerco comunicacional impuesto por el gran poder mediático transnacional" (párr. 70) ${ }^{29}$.

El problema consiste en que se trata de un desafío regulatorio todavía irresuelto siquiera por los Estados de países centrales, debido precisamente al hermético entramado de la economía global.

\section{ACERCA DE LAS ÉPICAS: IMPLICACIONES DEL INDIGENISMO Y DE LA INVOCACIÓN BOLIVARIANA}

Un relevamiento de la teoría sociológica suministra ilustraciones aleccionadoras a propósito de las elaboraciones destinadas a suprimir la hipótesis del conflicto al interior de cada sociedad para luego proyectarla sobre los compromisos intergubernamentales entre Estados cuyas poblaciones estarían sometidas a similares padecimientos. En este aspecto, las insistentes reivindicaciones sobre una "Patria Grande" responderían a las urgencias del inconsciente colectivo por forzar nexos de pertenencia parecidos a las que abonaron aquellas invocaciones al "nosotros" 30 y a la "comunidad" 11 en naciones europeas empobrecidas y humilladas por las condiciones derivadas del Tratado de Versalles, al cabo de la Primera Gran Guerra. Tales elucubraciones anticiparon el advenimiento del nazismo.

\footnotetext{
${ }^{29}$ Aquella VII Cumbre había planteado distintos objetivos: (a) en el área de producción de contenidos, incluyendo la previsión de un mecanismo de "seguimiento a los medios de comunicación con la finalidad de enfrentar la guerra mediática" (párr. 72); (b) en el área de infraestructura, para impulsar un "Proyecto ALBA Satélite" (párr. 66). La XI Cumbre diseñó los órganos que debían implementar aquellos objetivos y previó además la elaboración de un "Plan de Trabajo Conjunto".

30 A. Vierkandt (1934) examinó el sentido socio-político del "nosotros" en "Filosofía de la sociedad y de la historia".

${ }^{31}$ Hans Freyer (1944) discurrió largamente sobre el concepto de "comunidad". Véase: "La sociología ciencia de la realidad". En otro texto Freyer (1945) identificó el sentido estructural de la comunidad en su época con el concepto de "pueblo".
} 
En el caso del ALBA, las imágenes y los símbolos galvanizadores de la unión surgen como sublimación o mitificación del indigenismo (las "culturas ancestrales") y de las luchas por la independencia política.

Las fantasías indigenistas abrevan, como es sabido, en acervos históricos cargados de controversias que nunca terminan de saldarse. Al explorar esta memoria quedan en evidencia por lo menos dos registros que la "verdadera integración" del siglo XXI desechó sin tapujos. El primer registro repudiado fue el del hispanismo colonial. Y el segundo registro rechazado fue el que mitificó el mestizaje.

El hispanismo resultó inaceptable habida cuenta de los horrores cometidos bajo el manto de la evangelización de los indígenas.

Pero más dificultosa fue -y sigue siendo- la negación del mestizaje como emblema de unión, porque responde a una tradición intelectual que se prolongó hasta la segunda mitad del siglo XX. El ensalzamiento del mestizaje tuvo por objeto confrontar con la expansión imperialista norteamericana, pero partiendo del mismo enfoque racista que se fustigaba: si Estados Unidos de América habría construido su imperio a expensas de los pueblos originarios, América Latina podría contraponérsele y merecer un futuro promisorio debido a la simbiosis cultural generada por el entrecruzamiento racial de colonizadores y colonizados.

Sin embargo, la reificación del mestizaje presentó dos características que no se diferencian demasiado de la postura por una "verdadera integración" en el siglo XXI. Para empezar, la reivindicación del mestizaje también estuvo sustentada por una confrontación geopolítica. En segundo lugar, concluyó inexorablemente por apelar al delirio místico porque debió dar cuenta de un destino promisorio tanto para los mestizos como para la población no mestiza. Esta necesidad de incorporar a los no mestizos y básicamente a las generaciones descendientes de la inmigración europea más reciente había inducido a José Vasconcelos a idealizar el mestizaje como blasón de unidad para la población entera. De ahí el título de su libro "La Raza Cósmica”32.

32 Obra publicada en París y Barcelona en 1925. En un trabajo caracterizado por su erudición, José Ramiro Podetti rastrea el itinerario del pensamiento latinoamericano que mitificó el mestizaje a partir de la colonización española. En este camino sobresalen las figuras de Francisco García Calderón (1883-1953) y de José Vasconcelos (1882-1959), para resaltar algunas elaboraciones metafísicas inspiradas en los crisoles raciales que afloraron en Perú y 
Pero estas dos coincidencias acerca de las implicaciones en la operación discursiva que sacraliza tanto el indigenismo como el mestizaje no alcanzan a opacar una diferencia entre ambos emblemas. Ocurre que la reivindicación del mestizaje de alguna manera inspira una mirada condescendiente sobre la conquista y la colonización. Así se justifica el papel trascendental asignado a la síntesis interracial y, más aún, cuando se postula el advenimiento de una nueva cultura superadora o "transculturación"33 que habilitaría relaciones maduras con el resto del mundo.

De tal modo la narrativa sobre una "verdadera integración" es incompatible con la reificación del mestizaje. En cambio, emerge un indigenismo idealizado y a la vez simplificado al extremo ${ }^{34}$, con sorprendentes derivaciones. Ante todo, llama la atención un implícito paralelismo con la resurrección de Jesús en el sentido que la "verdadera" integración también operaría como una especie de redención, pero en este caso terrenal. Las etnias "originarias" o "ancestrales" inicialmente sacrificadas regresarían al tiempo presente representando o encarnando una especie de promesa de salvación para los pueblos oprimidos de América Latina.

¿De qué manera las culturas ancestrales infunden sus preceptos en el tiempo presente? Como se describe más adelante ${ }^{35}$, según los textos del ALBA y luego del GRUPO DE PUEBLA, su presencia está mediatizada por la sugestión que inspiran los conceptos de "Madre Tierra", "buen vivir" y "vivir bien". Tal mandato de las culturas ancestrales parece representar el anudamiento sagrado de la tierra y el cielo. $Y$ se trata de un mandato universal que no reconoce destinatarios particulares.

México respectivamente. Véase de dicho autor (2015): Cultura y alteridad. En torno al sentido de la experiencia latinoamericana.

${ }^{33}$ Es muy conocida la referencia de Bronislaw Malinowski al concepto de "transculturación" que había elaborado el célebre antropólogo cubano Fernando Ortiz. Al prologar el libro de este último "Contrapunteo cubano del tabaco y del azúcar", Malinowski adopta con entusiasmo el término "...que no contiene la implicación de una cierta cultura hacia la cual tiene que tender la otra, sino una transición entre dos culturas, ambas activas, ambas contribuyentes con sendos aportes, y ambas cooperantes al advenimiento de una nueva realidad de civilización" Podetti (2015, pp. 156-157). La convalidación funcionalista del concepto no puede opacar, sin embargo, la importancia que Ortiz atribuyó a las tensiones económicas y sociales generadas por las explotaciones económicas -típicamente la producción de azúcar y tabaco- sobre la población cubana de la época colonial. En este sentido véase: Gretel Philipp (2017).

${ }^{34}$ Este punto resulta muy sensible para la intelectualidad latinoamericana, considerando el aporte fundacional de José Carlos Mariátegui con su trabajo "El problema de las razas en la América Latina", en el que presentó la necesidad de contemplar la variable étnica pero vinculada estrechamente al sistema de clases sociales. Lo recuerda Patricia Funes en la ponencia citada más arriba. Véase José Carlos Mariátegui (2021).

${ }^{35}$ Véase más abajo el apartado 8 Regresión jurídica: el animismo. 
Es paradójico pero este rescate tiene sentido místico porque se inspira en la misma fuente de religiosidad que justificó el sometimiento de los indígenas. Como en la tradición católica, la salvación no estaría reservada sólo a los descendientes de indígenas, sino que incluiría a todos los latinoamericanos dispuestos a reconocer su sacrificio (copiando en otro contexto y por lo tanto falsificando la enseñanza de los Padres de la Iglesia que asignaron la promesa de salvación no sólo a los "circuncidados" o judíos sino a todos aquellos que reconocieran el milagro de la resurrección $\left.{ }^{36}\right)$.

De tal modo, una primera huella semántica va tiñendo el imaginario colectivo con el misticismo que recurre sin confesarlo a una simbología copiada de la tradición católica tan arraigada en América Latina.

La "verdadera integración" significaría entonces, ante todo, una especie de comunión laica convocante para todo individuo asentado en territorio latinoamericano y que, independientemente de su ascendencia étnica, estuviera dispuesto a tomar posesión de la herencia precolombina, esto es, a identificarse con ella rindiendo tributo a la Madre Tierra.

Cuando el indigenismo conjuga el sentido misional con la idealización del sujeto inspirador (pueblos ancestrales u originarios), ya bordea el cuadro de un delirio místico y por lo tanto imposible de confrontar en el debate de ideas. A esta dificultad se le superpone la pretensión de investigadores sociales que, abrumados por la depredación del medio ambiente, actualmente difunden en los organismos internacionales su propuesta para erigir a la naturaleza y, por extensión, a sus distintas manifestaciones en carácter de "sujeto de derecho" 37.

El segundo acervo hereditario es el que reúne a las invocaciones de próceres erigidos por los distintos países de la región como sus padres fundadores o padres de la patria. Otra vez hay aquí una re-significación ${ }^{38}$.

\footnotetext{
${ }^{36}$ Véase, por ejemplo, en el Nuevo Testamento, Los Hechos de los Apóstoles, capítulo 10 párrafos 44 a 48 ; y capítulo 11 párrafos 15 a 18.

${ }^{37}$ El autor examina esta cuestión en el apartado 8 Regresión jurídica: el animismo.

38 Enseña Waldo Ansaldi (1997) que "inventar una tradición significa buscar y encontrar en el pasado una clave que, re-significada, es capaz de dar cuenta de un proyecto actual. ¿Cuál será esa clave en nuestro caso (el de la integración latinoamericana en general)? Es usual apelar al proyecto bolivariano, trunco en el Congreso de Panamá (1826) pero retomado en más
} 
Salvando el caso de Bolívar, que incuestionablemente propulsó un proyecto político de alcance regional ${ }^{39}$, los otros nombres de próceres suelen acumularse para conformar una nómina ${ }^{40}$ bajo cuya inspiración los Jefes de Estado suscriben los textos convenidos en sus reuniones cumbres.

Frecuentemente las dos herencias se suman y sobrecargan para dar grandilocuencia y brillo a la proclama:

\begin{abstract}
Este acto simboliza las aspiraciones de independencia de los pueblos americanos, cuyas raíces se hunden profundamente en la historia de América, desde la resistencia indígena a los conquistadores emprendida por Tupaj Amaru, Tupaj Katari, Guaicaipuro, Diriangén y Miskut, pasando por las luces de soberanía encendidas por nuestros próceres Francisco de Miranda, Simón Bolívar, Antonio José de Sucre, Francisco de Morazán, José Martí, Eloy Alfaro Delgado y Augusto C. Sandino hasta nuestros días, donde América Latina se levanta recogiendo las banderas de libertad y justicia, de los que nos antecedieron (ALBA, 2007, párr. 7) ${ }^{41}$.
\end{abstract}

de una ocasión" (p. 65). Aquí Ansaldi cita a Ricaurte Soler: "Idea y cuestión nacional latinoamericana", Siglo Veintiuno Editores.

${ }^{39}$ En los Fundamentos Históricos de la Declaración de Caracas por la cual se crea la CELAC, se lee: “...16. Inspirados en el Congreso Anfictiónico de Panamá de 1826, acto fundamental de la doctrina de la unidad latinoamericana y caribeña, en el que nuestras jóvenes naciones soberanas plantearon la discusión de los destinos de la paz, el desarrollo y la transformación social del continente..." (párr. 16) Para un análisis histórico y crítico del proyecto bolivariano, en las antípodas de la narrativa sobre la "verdadera integración", véase de Luis Castro Leiva (1991): De la patria boba a la teología bolivariana.

40 Las nóminas difieren. Por ejemplo, la significativa referencia al papel de los próceres haitianos contenida en el párrafo 13 de los Fundamentos Históricos de la Declaración de Caracas no fue reproducida en todos los documentos posteriores. El mencionado párrafo dice: "13. Destacando el camino trazado por los Libertadores de América Latina y el Caribe hace más de doscientos años, un camino iniciado de manera efectiva con la independencia de Haití en 1804, dirigida por Toussaint Louverture, constituyéndose de esta manera en la primera República Independiente de la región. De la misma manera recordamos que la República de Haití liderada por su Presidente Alexandre Pétion, con la ayuda prestada a Simón Bolívar para la independencia de los territorios que en el presente conocemos como América Latina y el Caribe inició las bases para la solidaridad e integración entre los pueblos de la región" (párr. 13).

${ }^{41}$ Instrumento de adhesión suscrito por Daniel Ortega Saavedra, Presidente de la República de Nicaragua en la IV Cumbre de Managua, 11 de enero de 2007. Como se indicó más arriba, los listados de próceres van variando. Por ejemplo, en la Declaración Final de la IX Cumbre, dada el 19 de abril de 2010, a la invocación de próceres mencionada se agregan los nombres de: Bartolina Sisa, Manuela Sáenz, San Martín, O’Higgins, Petión, Hidalgo, Artigas y Toussaint L'Ouverture. 


\section{INSINUACIONES DE COOPERACIÓN EN CONTEXTOS CAMBIANTES}

Las evidencias acerca del peso de la economía global sobre los países periféricos es tan notoria que de tanto en tanto comenzaron a colarse -entre los denuestos al capitalismo imperialista y a sus instrumentos de política comercial y económicaalgunas insinuaciones aisladas sobre alguna posible interacción, aludiéndose por ejemplo a la realización por las Partes "de estudios que permitan identificar y evaluar los posibles espacios de interés común, para formular las estrategias que determinen sus relaciones intrarregionales, frente a terceros Estados, bloques de Estados, áreas de comercio u organismos internacionales" (ALBA-TCP, 2012a, párr. 15) ${ }^{42}$.

Esta iniciativa más tarde ganó en precisión porque fue acotada dentro de la Declaración de Guayaquil en la XI Cumbre, el 30 de julio de 2013:

11. Resaltar el interés y disposición del ALBA-TCP en establecer relaciones de cooperación con MERCOSUR, CARICOM y PETROCARIBE, especialmente a través de la complementación entre el Espacio Económico del ALBA-TCP (ECOALBA-TCP) y la Zona Económica de PETROCARIBE (ZEP). Promover un marco de concertación política y de complementariedad económica y productiva entre las naciones que conforman estos mecanismos de integración para integrar un espacio económico ampliado (párr. 32).

La figura inserta en el último párrafo acerca de la conformación de un espacio económico ampliado pareció prontamente un objetivo demasiado ambicioso, a la luz de la Declaración Final dada en la XIII Cumbre, el 14 de diciembre de 2014 en La Habana:

38. Diseñar estrategias y acciones concretas que permitan operacionalizar la construcción y desarrollo de la Zona Complementaria ALBATCP/PETROCARIBE/CARICOM/MERCOSUR como espacio de complementariedad económico-productiva. Este paso resulta importante para garantizar la sustentabilidad de los programas y acciones sociales que han elevado la calidad de vida de nuestros pueblos y que han sido el signo distintivo del ALBA-TCP desde su fundación (párr. 42).

\footnotetext{
${ }^{42}$ Acuerdo para la constitución del Espacio Económico del ALBA-TCP, artículo 1.
} 
El último párrafo es aleccionador, no sólo porque llama a diseñar estrategias y acciones concretas para una complementariedad económica-productiva con los países del cono sur agrupados como MERCOSUR (reiterando la mención al MERCOSUR en el párrafo 11 de la Declaración efectuada por la Cumbre precedente), sino porque reconoce que semejantes estrategias y acciones concretas servirían para garantizar la sustentabilidad de los programas y acciones sociales llevadas a cabo en el seno del mismo ALBA-TCP. De modo que la búsqueda de complementación económicoproductiva con estos terceros países se relaciona con las dificultades financieras ${ }^{43}$ que para entonces ya horadaban la viabilidad del proyecto inicial del ALBA-TCP ${ }^{44}$.

\section{TeXtos NORMATIVOS DEL ALBA QUE RESPONDEN A LA NARRATIVA ORIGINAL}

Las características de los instrumentos regulatorios explican la imposibilidad de implementar muchas de las concesiones, beneficios, ventajas o facilidades previstas o establecidas en ellos, según el caso, debido a que:

A. Las imprecisiones y otros defectos conceptuales hacen suponer que para el cumplimiento de lo acordado se debían haber adoptado compromisos complementarios o bien el Estado que otorgaba concesiones, beneficios, ventajas o facilidades no adecuadamente definidas hubiera tenido en cada caso que determinar si se cumplían los

\footnotetext{
43 “...la fuerte incidencia de productos primarios en la canasta exportadora de la región, en especial en América del Sur, pero también en varios países del Caribe, hizo que la caída en los precios internacionales de esos productos desde 2014 deteriorase los términos de intercambio, lo que redujo tanto el impulso por el lado de la demanda como el margen de maniobra externo por la disminución en el ingreso de divisas a la región. Entre 2013 (año previo a la caída de los precios internacionales de las materias primas) y 2019, el precio internacional promedio de los metales cayó un 12\%; el de los productos agrícolas un 17\%; y el del petróleo un 35\%" (Abeles, Pérez Caldentey y Porcile, 2020, p.160).

${ }^{44}$ La preocupación por la pérdida de sustento financiero reapareció en la Declaración de la XIV Cumbre de Jefes de Estado y de Gobierno del ALBA-TCP, pronunciada en Caracas el 5 de marzo de 2017: “...América Latina y El Caribe atraviesa una etapa crucial de su historia: los procesos democráticos populares, liderados por gobiernos, fuerzas políticas y movimientos de izquierda, enfrentan una nueva embestida del imperialismo, el capital transnacional y las oligarquías nacionales. El declive del hegemonismo imperial, los impactos de la crisis sistémica internacional y la caída de los precios de nuestros recursos de exportación, en particular de los hidrocarburos, abren nuevos desafíos. Son generados por las mismas fuerzas que crearon la pobreza, la exclusión y la dependencia de nuestras naciones y que nos impusieron invasiones y dictaduras para consolidar su poder (...) (párr. 4)".
} 
recaudos requeridos del lado de la contra-Parte para dar lugar a la eventual aplicación de la medida ${ }^{45}$;

B. Al no diferenciarse en cada materia negociada el componente comercial y el componente de cooperación, resultaba que las concesiones, beneficios, ventajas 0 facilidades comerciales podían quedar supeditadas a la previa implementación de compromisos de cooperación; y

C. Al estigmatizar, sobre la base de simplificaciones y falsedades, el contenido de los equívocamente denominados "tratados de libre comercio" que ya se difundían en el mundo durante la primera década del siglo XXI, los Estados Miembros quedaban inhibidos para emular distintas políticas y acciones que, en ausencia de tales descalificaciones, hubieran podido llevarse a cabo.

A continuación, se ilustran estas tres características con algunos ejemplos.

\section{VI.1. Imprecisiones y otros defectos conceptuales}

En muchos casos los compromisos comerciales y económicos expuestos nominalmente presentan una contundencia engañosa debido a la indefinición propia del compromiso y a la falta de referencias acerca de los criterios y modalidades a seguir para su perfeccionamiento.

Al respecto, el primer ejemplo está plasmado por la siguiente cláusula:

Los Gobiernos de la República Bolivariana de Venezuela y la República de Cuba eliminan de modo inmediato los aranceles o cualquier tipo de barrera no arancelaria aplicable a todas las importaciones del universo arancelario hechas por Cuba o Venezuela que sean procedentes de la República de Bolivia (ALBA-TCP, 2006, párr. 49)

\footnotetext{
45 Aquí se alude a las cláusulas que dan a entender la contracción de compromisos de aplicación inmediata y que sin embargo no son operativas. Por otro lado, figuran cláusulas explícitamente "programáticas", como la novena disposición general del Acuerdo para la Aplicación del ALBA-TCP entre los presidentes de Bolivia, Cuba y Venezuela (29 de abril de 2006): "Los Gobiernos podrán practicar mecanismos de compensación comercial de bienes y servicios en la medida que esto resulte mutuamente conveniente para ampliar y profundizar el intercambio comercial" (art. 9).
} 
El acceso irrestricto a los mercados venezolano y cubano para bienes físicos bolivianos no tiene su réplica en alguna obligación comercial contraída por Bolivia que pudiera dar lugar a evaluaciones acerca del trato especial y diferenciado a su favor y que, simultáneamente, le facilitara al gobierno boliviano recursos para negociar frente al eventual incumplimiento de dicho compromiso que, por lo tanto, queda planteado como una verdadera liberalidad.

Pero el alcance de la liberalidad es engañoso al menos por dos motivos. En primer lugar, como es obvio no debe leerse "importaciones procedentes" sino "originarias" de Bolivia, a menos que tanto Cuba como Venezuela tomaran el riesgo de importar bienes de otros orígenes a través de triangulaciones o deflexiones, lo que resultaría incomprensible. Pero el régimen de origen no es materia de negociación y, por lo tanto, se supone que toda importación procedente de Bolivia quedaría supeditada a las disposiciones de calificación de origen adoptadas por el país de la importación. En segundo lugar, el significado de "cualquier tipo de barrera no arancelaria" habría de estar siempre acotado por la negociación de medidas no arancelarias entre las mismas Partes a fin de fijar el compromiso de no introducir restricciones. ¿Cuáles serían entonces las medidas no arancelarias susceptibles de ser aplicadas por Cuba y Venezuela y que estos mismos países pudieran considerar como justificadas, esto es, no conceptualizadas como "barreras"? No sólo no están preestablecidas, sino que se carece de orientación o referencia con respecto a las regulaciones aplicables, independientemente de las disposiciones multilaterales vigentes para Cuba y Venezuela (las que, curiosamente, ni siquiera son objeto de referencia).

Un segundo ejemplo lo proporciona el Acuerdo para la constitución del Espacio Económico del $A L B A-T C P^{46}$. Al regular la política comercial, el grado de discrecionalidad reconocido a las Partes es de tal envergadura que dicha regulación podría entenderse ya no como aliento sino más bien como un obstáculo para la adopción de compromisos. Así surge del párrafo 11 de su artículo 2:

\section{Comercio con políticas arancelarias ajustadas a los requerimientos de} los países en desarrollo. La eliminación entre nuestros países de todas las barreras que constituyan un obstáculo a la complementación, permitiendo a los países subir sus aranceles para proteger a sus industrias nacientes o cuando

\footnotetext{
${ }^{46}$ Dado en la undécima Cumbre, el 4 de febrero de 2012.
} 
consideren necesario para su desarrollo interno y el bienestar de su población con el fin de promover una mayor integración entre nuestros pueblos.

Esta indefinición sobre el grado de discrecionalidad de las Partes podría suponerse que quiso ser matizado por una previsión, contenida en el artículo 3, para incorporar, al cabo de los dos primeros años de vigencia del Acuerdo, regulaciones de política comercial y de armonización productiva al estilo de los descalificados "Tratados de Libre Comercio". Asimismo, en este futuro e hipotético Régimen Normativo y Programático se incluiría también un régimen sobre solución de controversias. Pero resulta difícil imaginar cómo se habrían compatibilizado tales disposiciones con el artículo 16 del Acuerdo: "Las controversias que pudieran surgir entre las Partes, derivadas de la aplicación o interpretación de este Acuerdo, serán sometidas a negociaciones directas entre ellas. En caso de no ser resueltas por esta vía, serán sometidas a la decisión del Consejo Presidencial del ALBA-TCP”.

Al no existir constancias sobre la puesta en vigor del citado Acuerdo, no se presentó la oportunidad para resolver estas curiosas incongruencias.

\section{VI.2. Indiferenciación del componente comercial y del componente de cooperación}

El ejemplo a considerar es el de la resolución normativa de uno de los "principios y bases cardinales" del ALBA: el "trato especial y diferenciado que tenga en cuenta el nivel de desarrollo de los diversos países y la dimensión de sus economías, que garantice el acceso de todas las naciones que participen en los beneficios que se deriven del proceso de integración" (párr. 13) ${ }^{47}$.

El significado asignado a este "trato especial y diferenciado" no se compadece con el empleado comúnmente al contraerse compromisos internacionales de carácter comercial y económico. En estos últimos el sentido es el de "asimetría" en tanto los Estados beneficiarios del trato especial y diferenciado conceden en menor medida de lo que obtienen a cambio. En virtud de dicha asimetría es posible determinar en cada caso en qué consiste y cuál es la importancia relativa del referido trato especial y diferenciado.

47 Declaración Conjunta suscrita por los Jefes de Estado de Cuba y Venezuela el 14 de diciembre de 2004. https://www.albatcp.org/acta/declaracion-conjunta-venezuela-cuba/ 
En cambio, dentro del lenguaje del ALBA el significado es diferente porque resulta imposible detectar donde radica la asimetría. En principio se reconocen retórica y genéricamente las disparidades e insuficiencias. Pero a continuación cada Parte fija las prestaciones (concesiones, ventajas, beneficios o facilidades que otorgará a sus contra-Partes) sin que se pueda detectar cuál sería el criterio para determinar el carácter asimétrico de las contraprestaciones.

Distinto es el caso de la cooperación, cuando una Parte ofrece determinados servicios (por ejemplo, servicios médicos) y la contraparte ofrece recursos que hacen posible aquella prestación (por ejemplo, instalaciones).

Esta permanente confusión entre "comercio" e "inversiones" por un lado y "cooperación" por otro lado, sugiere un trato especial y diferenciado en materia comercial y económica que sin embargo no es tal, debido a que toda cooperación lleva consigo, por definición, un trato asimétrico. En definitiva, cuando los compromisos del ALBA exhiben ese trato asimétrico inevitablemente hacen referencia a las acciones de cooperación y no al comercio ni a las inversiones. Esta caracterización no es casual, sino que responde al fundamento "solidario" del ALBA que constituye el primer precepto y base cardinal de su narrativa:

El comercio y la inversión no deben ser fines en sí mismos, sino instrumentos para alcanzar un desarrollo justo y sustentable, pues la verdadera integración latinoamericana y caribeña no puede ser hija ciega del mercado, ni tampoco una simple estrategia para ampliar los mercados externos o estimular el comercio. Para lograrlo, se requiere una efectiva participación del Estado como regulador y coordinador de la actividad económica (párr. 12) ${ }^{48}$.

Esta combinación entre las nociones altruistas y la preservación del Estado como regulador tiene un resultado dual: la solidaridad resiste a las imposiciones de los mercados, pero, además, implica una simbiosis de intereses conjugados comunitariamente.

Cabe suponer entonces que la suposición sobre la viabilidad de un mecanismo de intercambios altruistas contribuyó para impedir que "se hiciera realidad" el Tratado de

\footnotetext{
${ }^{48}$ Véase la Declaración Conjunta suscrita por los Jefes de Estado de Cuba y Venezuela el 14 de diciembre de 2004 citada.
} 
Comercio de los Pueblos $(\mathrm{TCP})^{49}$ y los instrumentos previstos como ejes de la complementación: proyectos y empresas gran-nacionales.

La dificultad para encauzar en el ALBA dichos propósitos bajo un formato de integración económica indujo prontamente a un velado replanteo que apuntó a la progresividad de su aplicación:

Las Partes promoverán la creación de empresas gran nacionales, como máxima expresión de encadenamientos productivos que permitan establecer capacidades estructurales conjuntas en las redes de producción, distribución y comercialización dando prioridad al intercambio de materias primas, bienes de capital e intermedios. En tal sentido, se plantea como estrategia general la conformación y consolidación, en una primera etapa, de empresas mixtas binacionales en sectores específicos, en función de las condiciones que faciliten su nacimiento, para posteriormente ir incorporando progresivamente a otros países. Cada una de estas iniciativas debe estar precedida de la realización de los estudios de factibilidad que confirmen su sostenibilidad económica $(\text { art. } 8)^{50}$.

\section{VI.3. Confrontación equívoca con los Tratados de Libre Comercio}

Cuando el proyecto del ALCA que había apuntado a formalizar un acuerdo hemisférico de libre comercio estaba en curso de disolución, el emblema del ALBA como proyecto alternativo debió adaptarse a las nuevas circunstancias. Entonces toda la carga peyorativa fue puesta sobre los "tratados de libre comercio" (TLC) que a la época de la XI Cumbre del ALBA (febrero de 2012) ya se insinuaban como un formato de integración económica en franca difusión.

Precisamente dentro del Acuerdo para la constitución del Espacio Económico del ALBA-TCP, suscrito en ocasión de dicha XI Cumbre, abundan estas descalificaciones. En particular:

\footnotetext{
${ }^{49}$ Después de repetidos amagues, en la Décima Cumbre, realizada en Otavalo, Ecuador, el 25 de junio de 2010, los Estados Miembros seguían insistiendo: “...4. Confirmamos nuestro compromiso de hacer realidad el Tratado de Comercio de los Pueblos (TCP), afirmando la soberanía de los países de la región y la construcción de un modelo alternativo de soberanía económica expresado en una Nueva Arquitectura Financiera (SUCRE, Banco y Fondo del ALBA) para consolidar un sistema de intercambio y cooperación recíproco, solidario, participativo y complementario, que fortalezca nuestra soberanía alimentaria".

${ }^{50}$ Acuerdo para la constitución del Espacio Económico del ALBA-TCP, artículo 8.
} 
a) "Mientras los TLC imponen reglas iguales y recíprocas para grandes y chicos, el TCP plantea un comercio que reconozca las diferencias entre los distintos países a través de reglas que favorezcan a las economías más pequeñas" (art. 2 párr. 5);

b) "A diferencia de los TLC que persiguen la privatización de los diferentes sectores de la economía y el achicamiento del Estado, el TCP busca fortalecer el Estado como actor central de la economía de un país a todos los niveles enfrentando las prácticas privadas contrarias al interés público, tales como el monopolio, el oligopolio, la cartelización, acaparamiento, especulación y usura..." (art. 2 párr. 6):

c) “(...) Mientras los TLC buscan convertir a toda la humanidad en simples consumidores homogeneizando los patrones de consumo para ampliar así los mercados de las transnacionales, el TCP impulsa la diversidad de expresiones culturales del comercio" (art. 2 párr. 8);

d) “(...) En oposición al TLC que promueve la privatización de los servicios básicos del agua, la educación, la salud, el transporte, las comunicaciones y la energía, el TCP promueve y fortalece el rol del Estado en estos servicios esenciales que hacen al pleno cumplimiento de los derechos humanos": (art. 2 párr. 12);

e) “(...) A diferencia de los TLC que imponen una serie de ventajas y garantías a favor de las transnacionales, el TCP busca una inversión extranjera que respete las leyes, reinvierta las utilidades y resuelva cualquier controversia con el Estado al igual que cualquier inversionista nacional..."(art. 2 párr. 16);

f) “(...) Mientras los TLC promueven el patentamiento de la biodiversidad y del genoma humano, el TCP los protege como patrimonio común de la humanidad y la madre tierra" (art. 2 párr. 17);

g) “(...) A diferencia de los TLC que buscan patentar y ampliar la duración de las patentes de invenciones que son fundamentales para la salud humana, la preservación de la madre tierra y el crecimiento de los países en desarrollo, muchas de las cuales han sido realizadas con fondos o subvenciones públicasel TCP antepone el derecho al desarrollo y a la salud antes que la propiedad intelectual de las transnacionales" (art. 2 párr. 18). 
En primer lugar, todas las aseveraciones precedentes tienen una característica común: presumen que los TLC replican una misma normativa. Como es sabido y puede confrontarse fácilmente, ocurre lo contrario. Las disciplinas acordadas bajo este formato únicamente tienen en común las remisiones a los ordenamientos multilaterales de la Organización Mundial del Comercio (OMC). Más allá de esta necesaria confluencia normativa se presenta una gama muy ancha de opciones regulatorias para las distintas materias negociadas, dependiendo en cada caso de la capacidad de cada una de las Partes para hacer valer -o no- sus intereses prioritarios frente a la contraParte.

En segundo lugar, se supone que los TLC estarían identificados con los intereses de las corporaciones transnacionales, en abierta oposición con los intereses públicos. En cambio, el TCP sostendría en todos los casos la participación prioritaria de los Estados nacionales en la actividad económica regulada por el Acuerdo. Aquí es evidente la falsedad del argumento, pues una lectura por lo menos superficial de numerosos TLC celebrados por países en desarrollo puede dar cuenta de: un minucioso cuidado de las Partes en la fijación de excepciones a los programas de desgravación comercial; reservas de mercado sobre distintas materias; requisitos e incentivos de desempeño con respecto a las inversiones y al suministro de servicios críticos como los de telecomunicaciones; negación del trato nacional para la provisión de diverso tipo de servicios; no admisión del recurso al arbitraje para el caso de controversias referidas a determinadas cuestiones reguladas, como las relativas a defensa de la competencia; y, por lo demás, el acogimiento expreso de las Partes a las garantías ofrecidas por las disposiciones de los acuerdos multilaterales de la OMC.

Por otro lado, salta a la luz el anacronismo y luego la esterilidad de la citada dicotomía "público-privado" que subyace a la descalificación de los TLC.

En resumen, la retahíla del Acuerdo para la constitución del Espacio Económico del ALBA-TCP a propósito de los meneados "tratados de libre comercio" le dio la espalda a hechos consumados. En tal sentido, las condiciones por las que atraviesa la economía global en esta fase de su maduración imponen a los Estados de países periféricos una carga insoslayable: su articulación con empresas privadas de cuyos productos y servicios no pueden prescindir (en áreas tales como la energética, las telecomunicaciones, el transporte, los servicios financieros...) Y es a través de los TLC celebrados frente a países de mayor desarrollo en cuyo territorio se asientan las 
matrices de dichas empresas, que pueden encontrarse los términos compromisorios más apropiados para controlar el desempeño local de estas (tengan o no el rango de corporaciones transnacionales).

\section{DESDE LA “VERDADERA INTEGRACIÓN” hACIA LA "INTEGRACIÓN SOBERANA"}

La narrativa sobre una "verdadera integración" tomó nuevas formas en América Latina entrada la segunda década del siglo XXI aún en países bajo gobiernos no populistas y, por lo tanto, sin contar con apoyatura política ni jurídica suficiente. Su detonante fue el descalabro económico y social generado por la pandemia del COVID 19 y agudizado por la deficiente administración de los recursos públicos en distintos países de la región.

La pandemia del COVID 19 generó una incertidumbre generalizada que en el caso de sociedades periféricas como las de los países latinoamericanos se superpuso a la incertidumbre ya instalada como consecuencia de las dificultades para sobrellevar las convulsiones económicas y sociales preexistentes.

Este clima parece haber sido el telón de fondo para el "Manifiesto Progresista del Grupo de Puebla" firmado en febrero de $2021^{51}$. Si bien su texto incluye numerosas aserciones que podrían atribuirse a cualquier documento de orientación socialdemócrata, entre estas ideas emergen otras que las contradicen, expuestas en los numerales 8 ("Resistir y combatir la guerra híbrida") y 9 ("Rechazar a las guerras

${ }^{51}$ El documento declara como firmantes del mismo a los miembros de distintos órganos: el Consejo Ejecutivo, el Consejo Latinoamericano para la Justicia y la Democracia, el Grupo Parlamentario y el Centro de pensamiento Marco Aurelio García. Véase en: www.grupodepuebla.org/manifiestoprogresista/ Uno de los hitos fundacionales del Grupo de Puebla fue el autodenominado "Grupo Progresista Latinoamericano" fundado en México el 14 de julio de 2019 como "espacio de reflexión y de intercambio político en Latinoamérica" (párr. 1), esencialmente para sostener la "necesidad de diálogo en Venezuela y sobre hacer frente a la persecución judicial (lawfare)". En la nómina de sus fundadores aparecen numerosas personalidades que habían sido Jefes de Estado en distintos países latinoamericanos: Luís Arce y Evo Morales Ayma de Bolivia; Rafael Correa del Ecuador; Lula Da Silva y Dilma Rouseff de Brasil; Leonel Fernández de República Dominicana; Fernando Lugo del Paraguay; José Mujica del Uruguay; Ernesto Samper de Colombia; y Martín Torrijos de Panamá (véase la nómina completa de fundadores, entre los que también figura Alberto Fernández que más tarde sería designado Presidente de Argentina, en www.grupodepuebla.org). La alusión a Venezuela se explica como réplica de dichos líderes al denominado "Grupo de Lima" en tanto el "Grupo de Puebla" se instituyó para de algún modo sostener al Presidente Maduro en medio de los cuestionamientos internacionales generados por las prácticas dictatoriales y la vulneración de los derechos humanos que han caracterizado a su gobierno. Y la referencia al "lawfare" tuvo por objeto contrarrestar el descrédito público de algunos de los líderes mencionados con motivo de los procesamientos a los que habían sido sometidos en sus respectivos países por acusaciones de corrupción. 
jurídicas (lawfare ${ }^{52}$ )"). Aunque un contenido semejante al de los párrafos individualizados por ambos numerales ya figura en los documentos liminares del Grupo de Puebla, el Manifiesto se destaca por la contundencia de sus términos. En este aspecto el enemigo externo no sólo está localizado, sino que se le atribuye la adopción de una estrategia de dominación sin reparar en medios, es decir, por todos los medios. Es la guerra híbrida:

En el último tiempo, la región ha sido agredida por la llamada guerra híbrida, una iniciativa liderada por Estados Unidos que consiste en alterar el curso de nuestras democracias. La principal estrategia de esta nueva forma de guerra consiste en los golpes de Estado que, a diferencia del pasado no ocurren apelando a los militares, sino recortando las facultades de los Congresos y violando los derechos de los opositores con acciones como la violación de los domicilios, la represión generalizada y la intimidación en medios de comunicación y redes sociales. Tal agresión busca acomodar a América Latina dentro de la agenda geopolítica de Estados Unidos y puede incrementar y agudizar la pobreza, la miseria y el hambre. Esta nueva forma de golpe se puso en marcha contra Dilma Rousseff, Fernando Lugo, Manuel Zelaya y Evo Morales (núm. 8) ${ }^{53}$.

Obsérvese una vez más la extraordinaria magnitud del poder asignado al enemigo externo (Estados Unidos de América), a tenor de su disposición para emprender una guerra por todos los medios y que incluiría la capacidad para filtrarse dentro de las fronteras utilizando recursos internos del país agredido. Dicho argumento se describe

${ }^{52}$ Expresión inglesa que fusiona la palabra "ley" (law) con otra palabra inexistente en español por la cual se alude a la guerra (war) pero poniendo énfasis en las formas de combate, atendiendo a los recursos o a los procedimientos utilizados (warfare). Así resulta una voz que describe acciones de guerra emprendidas a través de la utilización de recursos o procedimientos jurídicos.

53 "Manifiesto Progresista del Grupo de Puebla" citado, numeral 8. Según Barrios Rodríguez (2019) "...lo que se presenta como guerra híbrida no es en realidad una forma novedosa de enfrentar a los enemigos ya que la fusión entre la guerra tradicional o convencional y la de tipo irregular, así como la incorporación de mecanismos no estrictamente militares, resultan prácticas que se actualizan, pero que pueden ser rastreadas desde tiempos inmemoriales. A las objeciones que se han planteado al término relacionadas con lo hasta ahora expuesto, considero pertinente agregar que la propia conceptualización nos permite observar el carácter performativo de la enemistad contemporánea, de la redefinición constante de amenazas" (párr. 8). 
en este punto del Manifiesto de manera genérica, aludiendo a los instrumentos de los que puede valerse el citado enemigo externo.

Pero el párrafo siguiente aporta mayor precisión porque da cuenta en particular de un recurso del país agredido, que al ser contaminado por la estrategia enemiga permite que los ataques sean consumados exitosamente. Se trata, ni más ni menos, que del ordenamiento jurídico vigente en cada uno de los países sometidos por la agresión imperialista. $Y$ debe tenerse muy en cuenta cuál es la precisa expresión utilizada para desarrollar este argumento: "guerra jurídica (lawfare)" y no meramente "guerra judicial".

El concepto "guerra jurídica (lawfare)" es novedoso porque marca la modificación sustancial de uno de los objetivos inicialmente perseguidos por la "verdadera integración". A partir de esta propuesta, se presume que no cabría concebir a la "verdadera integración" sin haber desmantelado previamente la arquitectura jurídica interna de cada uno de los Estados afectados por esa supuesta intromisión imperialista. Dice el párrafo 9 del Manifiesto:

El Grupo de Puebla rechaza las guerras jurídicas (lawfare) que hacen parte de la guerra híbrida y han buscado recortar los derechos de organizaciones, movimientos o partidos progresistas. Estos procesos que se vienen adelantando con apoyo de Estados Unidos, contra dirigentes progresistas de la región buscan impedirles elegir y ser elegidos mediante el recorte de sus derechos al debido proceso y la estigmatización mediática por poderes fácticos que han desplazado los espacios democráticos ocupados por los partidos. Los y las líderes y lideresas progresistas tienen pleno derecho a ejercer su liderazgo con garantías para su vida, libertad, movilidad, expresión y arraigo geográfico. Recordamos que el poder judicial pertenece al pueblo, por ende, debe rescatarse como un servicio público con jueces que defiendan este poder popular de postulados sectarios en contra de la ciudadanía, líderes y lideresas opositores y en beneficio de los gobiernos de turno $(\ldots)^{54}$.

Estos textos indican que, ante la comprometida situación de líderes "progresistas" que habían sido protagonistas del ALBA, la estrategia del enemigo (la guerra híbrida y, como parte de ella, la guerra jurídica) impone un cambio de perspectiva. Aquella

\footnotetext{
${ }^{54}$ Manifiesto Progresista del Grupo de Puebla citado, numeral 9.
} 
"verdadera integración"55 tendría que ser reimpulsada pero luego de la recuperación del poder político interno frente a la acción de "poderes fácticos que han desplazado los espacios democráticos ocupados por los partidos". Así se desprende del párrafo 26 del Manifiesto:

26. Promover la integración latinoamericana soberana. Los espacios de integración regional deben tener como objetivos principales la preservación de la región como zona de paz, la construcción de ciudadanía, la promoción del desarrollo común, la vigencia de los derechos humanos, la consolidación de la soberanía y el fortalecimiento del mercado regional. De igual modo, resulta indispensable reimpulsar la autonomía frente al Fondo Monetario Internacional (FMI) y las instituciones del capital financiero internacional, como las agencias calificadoras de riesgo, las cuales, bajo la amenaza de revisar evaluación por país, provocan crisis cambiarias y ponen en jaque el actuar soberano de la política económica. Igualmente, es necesario priorizar los derechos humanos frente a las obligaciones derivadas de los tratados de comercio e inversión y vincularlos al respeto de estándares sociales y ambientales, evitando que los procesos de arbitraje internacional vulneren los derechos de las personas, los pueblos y la naturaleza ${ }^{56}$.

Al multiplicarse los fantasmas (el FMI, el capital financiero internacional, las agencias calificadoras de riesgo, los tratados de comercio e inversión, las instancias de arbitraje internacional...) se supone que aumentará la necesidad -y el reclamo- de protección en las poblaciones desamparadas.

Entonces el discurso en pos de una integración económica queda en suspenso, habida cuenta de los desafíos que impone la infiltración de un enemigo multifacético en el frente interno de cada país.

${ }^{55}$ En tal sentido, el "proceso de integración" se menciona, por ejemplo, en el numeral 10 del mismo Manifiesto: "Defender a Cuba, Nicaragua y Venezuela de las agresiones e injerencias de potencias o terceros Estados. Varios de los países de la región han sido objeto de acciones tendientes a la desestabilización a través de la imposición de bloqueos, sanciones económicas y políticas unilaterales contrarias al derecho internacional. Este tipo de posturas anacrónicas y caducas son aún más graves en el contexto de la crisis sanitaria pues afectan el acceso a insumos, medicinas y medios para la contención de la pandemia. El Grupo de Puebla considera estas posturas como agresiones contra los segmentos más vulnerables de nuestros pueblos, además de una amenaza contra el proceso de integración. El progresismo promueve salidas en consonancia con la solución pacífica de conflictos, la no intervención y el apoyo a soluciones democráticas, pacíficas y negociadas".

${ }^{56}$ Manifiesto Progresista del Grupo de Puebla citado, numeral 26. 


\section{REGRESIÓN JURÍDICA: EL ANIMISMO}

Retomando el texto del párrafo 26 del Manifiesto, se observa que no sólo reafirma la identidad del enemigo externo, sino que avanza en la caracterización de sus distintos rostros sin dejar resquicios:

a) El sistema financiero internacional, englobando al FMl (que, como es sabido, constituye un organismo público internacional de tipo intergubernamental del cual los países latinoamericanos forman parte) y a instituciones privadas como son las calificadoras de riesgo;

b) Los tratados internacionales de comercio e inversión, en tanto incluyan compromisos que afecten derechos humanos; y

c) Los procesos de arbitraje internacional en tanto vulneren los derechos de las personas, los pueblos y la naturaleza.

Aquí habría que poner de relieve las referencias a los derechos conculcados y su envergadura: derechos humanos, derechos de las personas, de los pueblos y la naturaleza.

Entonces se impone la pregunta: ¿cuál es el sentido de puntualizar que la validez de tratados internacionales y de sentencias arbitrales pueda ser objeto de impugnación bajo el argumento de la vulneración de derechos humanos? ¿Ello no debería darse por sentado? ¿O acaso se trata de abrir una compuerta para desacreditar a tratados y procesos arbitrales en vigencia denunciándolos sistemáticamente por el hipotético menoscabo de "determinados" derechos humanos?

El texto, como tantos otros del ALBA y del Grupo de Puebla que denuncian el arrasamiento de derechos y culturas ancestrales, debería leerse como un entrecruzamiento discursivo destinado a obtener mayor adhesión. Ni el indigenismo ni la protección de la vida humana y de la biodiversidad son blasones exclusivos del ALBA y del Grupo de Puebla, pero el intento de captura de distintas líneas discursivas amplía la onda expansiva de su seducción política.

Este propósito de captura discursiva, en el caso de la defensa de la vida humana y de la biodiversidad frente a la depredación y contaminación ambientales, se potencia por la progresiva ampliación de los criterios legales, jurisprudenciales y doctrinarios 
aceptados universalmente para incluir distintas "generaciones" de derechos, haciendo cada vez más lábil su cobertura semántica ${ }^{57}$.

Por ejemplo, los estándares sociales y ambientales (a los que hace referencia este párrafo del Manifiesto) pueden hoy día concebirse -en muchos casos justificadamente- como garantías de supervivencia para la especie y la biodiversidad y por lo tanto han de ser guarecidos catalogando el derecho a su invocación también como "derechos humanos" 58 .

Pero estas reivindicaciones tienen, como tantas otras, dos caras contrapuestas. Al respecto la narrativa contestataria del Grupo de Puebla bordea una peligrosa mimetización con las restricciones en materia de certificaciones y trazabilidades que adoptan los gobiernos de sociedades centrales y que directa o indirectamente se justifican por la necesidad de preservar la vida humana y la biodiversidad. Tales certificaciones y trazabilidades -y cuya exigencia incluso representa una aplicación extra-territorial de la legislación interna- perjudican a numerosas actividades productivas localizadas en la periferia porque obstaculizan el acceso de sus productos a los mercados así protegidos.

En todo caso los reclamos no deberían pasar por alto la posibilidad de atender a posiciones más ponderadas expuestas en el curso de distintas disputas en el Sistema de Solución de Diferencias de la Organización Mundial del Comercio (OMC). Los árbitros han dictaminado reiteradamente que las acciones estatales unilaterales no pueden justificarse por la mera invocación del derecho de los Estados Miembros a

${ }^{57}$ En el progresivo enriquecimiento conceptual de la protección de los derechos humanos a partir de la Declaración Universal de 1948, fue altamente significativo el reconocimiento de derechos económicos, sociales y culturales caracterizados como derechos humanos de segunda generación por el Pacto Internacional precisamente denominado "de Derechos Económicos, Sociales y Culturales" (PIDESC, según la sigla en español). Este Tratado surgió de la Asamblea General de la ONU (Resolución 2200 A (XXI) el 16 de diciembre de 1966 y entró en vigor el 3 de enero de 1976. Fue completado con un Protocolo Facultativo aprobado el 10 de diciembre de 2008 y vigente desde el 5 de mayo de 2013, con el objeto de fijar los procedimientos de denuncia e investigación destinados a proteger el cumplimiento en su integridad de los derechos indicados.

${ }^{58}$ Según la ilustrativa síntesis presentada por la Agencia de la ONU para los Refugiados, los derechos humanos postulados a título de "tercera generación" (derecho a la paz, al desarrollo, a la libre determinación y a un ambiente sano y ecológicamente equilibrado) "están motivados por una serie de preocupaciones globales propias de finales del siglo XX y principios del XXI, principalmente el deterioro del medio ambiente y sus efectos negativos en la calidad de vida de las personas" (www.eacnur.org). 
resguardar bienes públicos tan valorados como la preservación de sus recursos naturales no renovables.

En efecto, la interpretación prevaleciente en el Sistema de Solución de Diferencias de la OMC sigue los cánones de una lectura sistemática de las disposiciones insertas en los distintos Acuerdos Multilaterales que la componen, sin dejarse arrastrar por la mera invocación a determinados principios. De modo que se han rechazado como improcedentes distintas prácticas comerciales restrictivas que, más allá de las alusiones a la preservación de recursos naturales no renovables, demostraron ser desproporcionadas o innecesarias ${ }^{59}$.

En cambio, la asunción de posiciones descontextualizadas ciñéndose a la letra de principios o valores liminares puede conducir a soluciones injustas. Es el caso de la interpretación textual del artículo XX b) del GATT que autoriza a los Estados Miembros la adopción de medidas destinadas a "proteger la salud y la vida de las personas y de los animales o para preservar los vegetales". En tal sentido, se ha sostenido que el mencionado artículo XX (b) del GATT "permite, de forma explícita, que los integrantes de la OMC adopten medidas inconsistentes con el GATT para hacer frente a problemas sociales y ambientales, siempre y cuando la medida se aplique de forma imparcial y sea necesaria ${ }^{60}$.

59 Esta jurisprudencia se difundió internacionalmente por el caso de los pronunciamientos arbitrales con motivo de las restricciones de China a la exportación de minerales ("tierras raras") cuyos derivados se utilizan para las industrias informáticas: "CHINA-Measures Related to the Exportation of Various Raw Materials" 30th January 2012 (WT/DS394/AB/R; WT/DS395/AB/R; y WT/DS398/AB/R). Pero la misma línea argumental que requiere una demostración de razonabilidad a fin de justificar restricciones -aunque se invoque la protección de recursos no renovables- ingresó al campo doctrinario a propósito de la pandemia por el COVID 19. Así, al difundirse la adopción de medidas unilaterales de carácter restrictivo sustentadas por la necesidad de administrar los recursos terapéuticos invocando el artículo XI.2 (a) del GATT, la Secretaría de la OMC produjo un documento muy ilustrativo cotejando dicha disposición con la del artículo XX (b) del mismo GATT. Según esta interpretación del organismo multilateral, en el caso del artículo XX (b) y a diferencia de las medidas previstas por el artículo XI.2 (a), el Estado Miembro que invoca la protección de los recursos naturales debe asumir la carga de la prueba que sostenga la razonabilidad de sus restricciones. Ha de probar la importancia de los intereses o valores en juego y luego la contribución de las medidas aplicadas para el logro del objetivo que se persigue. En esta instancia los Estados Miembros afectados tienen el derecho de sugerir alternativas razonables, técnica y financieramente viables para el Estado Miembro que pretenda imponer dichas restricciones y que aseguren el mismo nivel de protección al que se aspira (WTO: "Export Prohibitions and Restrictions Information Note", 23rd April 2020, p. 12).

60 Así, Wei Zhuang (2016) "Hacia un acuerdo comercial para regular los incentivos a las energías renovables". 
Teniendo a la vista de las ponderaciones precedentes, cabe suponer que el desapego a la normativa multilateral puede ocasionar daños adicionales cuando el nivel de protección o resguardo está fundado en la postulación de "la naturaleza" en tanto sujeto de derecho. Esta última idea tiene afinidad con las alusiones a la "madre tierra" en las Declaraciones de las Cumbres del ALBA, al menos cuando la "madre tierra" es erigida, explícita o implícitamente, como sujeto de derecho al que debería prodigarse máxima protección.

Esta mutación conceptual que reconoce a la naturaleza el carácter de sujeto y ya no de objeto de derechos, fue materia de análisis en un documento de CEPAL ${ }^{61}$ que tomó como modelo el texto de la Constitución del Ecuador: “...toda persona, comunidad, pueblo o nacionalidad podrá exigir a la autoridad pública el cumplimiento de los derechos de la naturaleza',62.

Dentro de esta tesitura, los autores del documento de CEPAL citan a Leonardo Boff ${ }^{63}$ para matizar las implicaciones del precepto:

"Cuando se postula que existen valores propios en la Naturaleza, no se niega que los humanos adjudiquen valores, sino que se acepta que los demás seres vivos poseen unos que son inherentes e independientes de la utilidad para las personas. Se rompe con el utilitarismo antropocéntrico. No se intenta caracterizar ese valor, ni precisarlo detalladamente, ya que cualquier movimiento en esa dirección nos lleva de regreso a las interpretaciones humanas. Es suficiente reconocer que en el ambiente se encuentran valores inherentes a los seres vivos y los ecosistemas..." (pp. 8-9)

Adjudicar a la Naturaleza la calidad de "sujeto de derechos" tiene aquí una implicación fundamental, porque abraza genéricamente a los derechos humanos en el sentido que, como surge tanto de los documentos del Grupo de Puebla como de las interpretaciones de Boff y Gudynas hechas suyas por los autores del documento de CEPAL, se trata de una "visión holística e integradora del ser humano".

${ }^{61}$ CEPAL: "La tragedia ambiental de América Latina y el Caribe", octubre 2020.

62 Constitución del Ecuador, artículo 71. Los autores del documento de CEPAL citan como fuente doctrinaria el trabajo de Eduardo Gudynas: "Los derechos de la naturaleza ante los extractivismos sudamericanos", que se basa en el curso que el autor y Alberto Costa dictaron en FLACSO, Quito, los días 11 y 12 de julio de 2016 titulado "Los derechos de la naturaleza y los extractivismos".

63 Leonardo Boff (2012) El cuidado necesario

${ }^{64}$ CEPAL, obra citada, páginas 8 y 9. 
¿Cuáles serían los fundamentos para evaluar si en un caso determinado se vulneran derechos humanos en su sentido más extenso? El Manifiesto Progresista del Grupo de Puebla lo explicita retomando aquella primera inspiración indigenista para una "verdadera integración":

22. Incluir el buen vivir o vivir bien como paradigma. Retomando las enseñanzas de los pueblos originarios se debe adoptar el concepto de sumak kawsay (buen vivir) o suma qamaña (vivir bien) como marco de referencia para el mejoramiento de la calidad de vida dentro de una hermandad histórica, cultural y espiritual. Esta noción de los pueblos originarios andinos coincide con la propuesta del Papa Francisco de estimular la fraternidad global dejando de lado la "cultura de los muros" que termina por esclavizar a los que los construyen encerrándose dentro de sus propias cárceles, sin dejar lugar al reconocimiento del "otro", base de la convivencia global ${ }^{65}$.

Obsérvese la significación heurística que se asigna a las enseñanzas de las culturas precolombinas resumidas en frases como las del buen vivir y vivir bien, adjudicándoles la categoría de directivas de "hermandad" o "fraternidad" y nuevamente asociadas a preceptos de la Iglesia Católica.

¿Pero cuál es el margen para que una medida o práctica económica pueda ser considerada incompatible con esas directivas y valores y así dar lugar a su impugnación por resultar inconciliable con los derechos humanos?

En otros términos: ¿cómo aventar el riesgo de la imposición de arbitrariedades en nombre de tan altos valores o derechos esenciales presuntamente conculcados?

El alerta surge del propio Manifiesto en aquella frase admonitoria: "Recordamos que el poder judicial pertenece al pueblo, por ende, debe rescatarse como un servicio público con jueces que defiendan este poder popular de postulados sectarios en contra de la ciudadanía, líderes y lideresas opositores y en beneficio de los gobiernos de turno" $\left(\right.$ párr. 9) ${ }^{66}$.

Por lo demás, al aludir a jueces que en lugar de defender el poder popular responderían a directivas sectarias y, en general, a poderes fácticos, y calificar a la

65 El párrafo indicado del Manifiesto Progresista finaliza con un llamado de pie de página que remite a la Encíclica Fratelli Tutti, 2020.

${ }^{66}$ Manifiesto Progresista, párrafo 9. 
estrategia del enemigo (neoliberalismo) como atentatoria de la vida ${ }^{67}$, el Manifiesto adquiere un tono de proclama revolucionaria.

En definitiva, la postulación de "guerras híbridas" y el ostensible pensamiento animista para la adjudicación de un estatuto subjetivo a los "derechos de la Naturaleza" parecen conjugarse como construcción de un discurso que ya no tiende a justificar algún proyecto de integración económica, sino que procura seducir a poblaciones cuyas condiciones de vida han sido severamente dañadas y que por ello deberían estar dispuestas a convalidar verdades reveladas.

Es al menos cuestionable semejante suposición de animismo a las etnias precolombinas. Este tipo de creencia no se deriva necesariamente de la inclinación por armonizar de algún modo la vida social tanto con las promesas como con las restricciones propias de la naturaleza. En efecto, si se recorren los distintos aspectos del comportamiento social característico de distintas etnias precolombinas, podrá encontrarse directa inspiración para las iniciativas de nuestro tiempo encaminadas a instalar economías "circulares", esto es, reacias a la generación de residuos y contaminantes $\mathrm{y}$, por lo tanto, proclives a la preservación y regeneración de los recursos no renovables ${ }^{68}$.

Así, pese al rudimentario animismo que le asignan los promotores de la "integración soberana", las culturas precolombinas parecen haber trabajado durante siglos en la formación de una conciencia sobre la conexión o armonización -y no tanto la identificación- con los recursos naturales ${ }^{69}$. En el ejercicio de esa templanza cobran pleno sentido sus invitaciones al altruismo ${ }^{70}$.

67 En el preámbulo del Manifiesto se lee, a propósito del "modelo neoliberal": "Este modelo
incompatible con la vida debe sustituirse por uno que reivindique la solidaridad, la justicia y las
formas de democracia sustantivas. Nos urge un nuevo rumbo para los pueblos de América
Latina, el Caribe e Iberoamérica".
68 "El modelo de economía circular es restaurativo y regenerativo, se alinea con el modelo
ecuatoriano basado en la economía social y solidaria con el fin último de alcanzar el "sumak
kawsay" (buen vivir")" ("Libro Blanco de Economía Circular de Ecuador", publicado por el
Ministerio de Producción, Comercio Exterior, Inversiones y Pesca en su sitio web el 12 de mayo
de 2021 , página 32).
69 El sitio web de la cancillería boliviana publicó a fines de 2018 una recensión de preceptos
culturales extraídos de los pueblos ancestrales arraigados en su territorio, bajo el título "Bases
de la Filosofía del Vivir Bien". Allí se lee: "Vivir Bien o Buen Vivir, es la vida en plenitud. Es
saber vivir en armonía y equilibrio, en armonía con los ciclos de la Madre Tierra, del cosmos, de
la vida y de la historia, y en equilibrio con toda forma de existencia. Y ese justamente es el
camino y el horizonte de la comunidad, implica primero saber vivir y luego convivir. No se 
En cambio, atribuir a la naturaleza el carácter de sujeto de derecho deriva en el problema de legitimación. ¿Quiénes serían los intérpretes autorizados para ponderar los actos de agresión y la magnitud del daño a su integridad? Es decir: ¿quiénes podrían invocar esa potestad para erigirse como voceros reconocidos? ¿Y cuáles serían los criterios que convalidarían la interpretación en cada caso?

\section{CONCLUSIONES}

1. El ALBA forjó una poderosa narrativa que abogó por una integración entre países empeñados en obstaculizar la imposición del sistema económico internacional para internacionalizar los mercados internos. Su capacidad de seducción se afirmó al presentarse como alternativa a un programa de integración "hemisférica" pergeñado en Estados Unidos de América. Tuvo además el respaldo de los recursos generados por la producción y exportación de hidrocarburos. Pero al disolverse aquel proyecto norteamericano que había sido el objeto de los pronunciamientos anti-imperialistas y ya esfumados los recursos destinados a sostener sus emblemas, curiosamente la misma narrativa subsiste y bajo determinadas condiciones aún parece perseverar.

2. Para ponderar la alta resonancia discursiva inicial y el motivo de credibilidad despertado por la narrativa sobre una "verdadera integración", deberían enfocarse sus principales focos de atención: el de la entidad política y económica del colectivo intergubernamental cuya edificación se propuso; y, simultáneamente, las marcas de identidad propia con motivo de la confrontación idealizada frente a un poder externo supuestamente omnímodo.

3. Plantados en un contexto adverso dentro de la misma región que ya reproducía nítidamente las nuevas condiciones de producción prevalecientes a escala mundial, para contrapesar el pensamiento instalado los adalides del ALBA procuraron remover discursivamente los fundamentos teóricos del sistema económico internacional. En tal sentido empezaron atribuyendo carácter

puede Vivir Bien si los demás viven mal, o si se daña la Madre Naturaleza. Vivir Bien significa comprender que el deterioro de una especie es el deterioro del conjunto" (párr. 1).

70 La publicación mencionada por la cita precedente ofrece una descripción del "Suma Churaña, suma Katukaña: Saber dar y saber recibir. Reconocer que la vida es la conjunción de muchos seres y muchas fuerzas. En la vida todo fluye: recibimos y damos, la interacción de las dos fuerzas genera vida. Hay que saber dar con bendición, saber dar agradecimiento, por todo lo que recibimos. Agradecer es saber recibir: recibir el brillo del Padre Sol, la fuerza de la Madre Tierra, fluir como la Madre Agua y todo lo que la vida nos da" (párr. 16). 
"verdadero" a su propuesta de integración económica frente a las legitimadas por el orden multilateral. Luego alinearon esta categoría lógica de "verdad" con otra aspiración: la de una revisión "lógica" de los fundamentos para la formación y reproducción del capital. ¿En qué consistió esta revisión? Desde un principio se puso de relieve el espíritu altruista o solidario -en sentido subjetivo- que por su reflejo en los procesos de decisión política y en el criterio de distribución de beneficios ("comercio justo") pareció afín al añejo principio inspirador de la "economía social" concebida originariamente en países desarrollados para fomentar las actividades privadas sin fines de lucro. Más adelante aquel llamado al altruismo fue sustituido por la proclama de una meta "socialista" que sin embargo nunca llegó a ser elaborada.

4. La contienda mítica del ALBA con el enemigo externo fue sostenida por una épica indigenista (consagratoria de las culturas precolombinas) y por una épica libertaria en el sentido bolivariano, esto es, destinada a enaltecer las gestas de independencia libradas en el siglo XIX. Es posible que estas épicas descontextualizadas hayan perdido eficacia persuasiva a medida que el desarrollo de las tecnologías digitales fue facilitando el acceso de poblaciones masivas -aun las carenciadas- a contenidos diseñados y difundidos mediante dispositivos móviles. En este aspecto a los usuarios digitales les debe resultar cada vez más difícil aceptar que las acciones dirigidas a reducir los efectos adversos de la internacionalización de los mercados internos puedan circunscribirse a porfías guiadas por mandatos ancestrales y entre gobiernos 0 empresas localizadas en distintos territorios físicos.

5. Sin embargo, las mitologías elaboradas alrededor del acervo indigenista y del homenaje a las gestas por la independencia política libradas en el siglo XIX demostraron su hálito seductor como encuadre ornamental de las proclamas realizadas periódicamente por los Jefes de Estado del ALBA. En particular, la mitología indigenista todavía exhibe un atractivo especial al amalgamar disimuladamente el hálito de las culturas precolombinas con los mensajes misionales del catolicismo.

6. En todo caso la pretendida conversión retórica desde el capitalismo hacia una economía solidaria contrastó con el diseño de los instrumentos de política económica y comercial que debían ser objeto de las concertaciones 
intergubernamentales. Al examinarlos con cuidado se advierten gruesos defectos en la concepción jurídica; una sistemática confusión entre los mecanismos de integración y de cooperación económica; y argumentos descalificatorios de los tratados de libre comercio de última generación, aunque intentaran reproducirse algunos de sus instrumentos típicos de política comercial. De ahí que finalmente los únicos resultados mensurables del ALBA se hayan circunscripto a distintas acciones de cooperación o prestaciones no retribuidas.

7. El "Grupo de Puebla" representa la radicalización final de la narrativa introducida por el ALBA. En tal sentido supedita la viabilidad de una "verdadera integración" al previo desmembramiento del orden institucional interno ya supuestamente degradado en cada país por la intromisión imperialista. Esta degradación se atribuye a una estrategia de arrasamiento por todos los medios posibles o "guerra híbrida" y, en particular, por la "guerra jurídica (lawfare)", esto es, la desnaturalización de los ordenamientos legales y las instituciones judiciales con el fin de perseguir y condenar a líderes catalogados como "progresistas"

8. Al enemigo externo se le atribuyen atropellos sistemáticos a los derechos humanos y a la integridad de la Naturaleza. Del mismo modo que con la cuestión del indigenismo, el llamado a defender a ultranza la vida humana y la preservación de los recursos naturales remiten a principios que exceden los objetivos del ALBA y del Grupo de Puebla. Con la captura y apropiación de estas líneas discursivas se hace notoria la pretensión de expandir el ámbito de seducción política, si bien los criterios utilizados para fundamentar las eventuales intervenciones gubernamentales ante la vulneración de derechos tan esenciales ponen el sello a su concepción autoritaria.

\section{REFERENCIAS BIBLIOGRÁFICAS}

Abeles, M., Pérez Caldentey, E., y Porcile, G. (2020). La crisis del COVID-19 y los problemas estructurales de América Latina y el Caribe: responder a la urgencia con una perspectiva de largo plazo. Revista de la CEPAL, (132). https://repositorio.cepal.org/handle/11362/46838

Alianza Bolivariana para los Pueblos de Nuestra América (ALBA) (2010). Manifiesto Bicentenario de Caracas. Declaración Final de la IX Cumbre del ALBA. https://revistas.unlp.edu.ar/aportes/article/view/3395 
Alianza Bolivariana para los Pueblos de Nuestra América (ALBA) (2008). Conceptualización de proyecto y empresa GRANNACIONAL en el marco del ALBA. https://www.albatcp.org/acta/conceptualizacion-de-proyecto-y-empresa-grannacionalen-el-marco-del-albal

Alianza Bolivariana para los Pueblos de Nuestra América (ALBA) (2007). Adhesión de Nicaragua al ALBA. https://www.albatcp.org/acta/adhesion-de-nicaragua-al-alba/

Alianza Bolivariana para los Pueblos de Nuestra América-Tratado de Comercio de los Pueblos (ALBA-TCP). (2020). Declaración de la XVIII Cumbre del ALBA-TCP en el XVI aniversario de su fundación. https://www.albatcp.org/2020/12/14/declaracion-cumbrealbatcp-aniversario-fundacion/

Alianza Bolivariana para los Pueblos de Nuestra América-Tratado de Comercio de los Pueblos (ALBA-TCP) (2017a). Declaración de la XIV Cumbre de Jefes de Estado y de Gobierno del ALBA-TCP. https://oilac.jursoc.unlp.edu.ar/images/ALBA/XIV-CumbreALBA.-MARZO-2017.pdf

Alianza Bolivariana para los Pueblos de Nuestra América-Tratado de Comercio de los Pueblos (ALBA-TCP) (2017b). Acuerdo para la aplicación del ALBA-TCP. https://www.albatcp.org/acta/acuerdo-para-la-aplicacion-del-alba-tcp/

Alianza Bolivariana para los Pueblos de Nuestra América-Tratado de Comercio de los Pueblos (ALBA-TCP). (2014). Declaración final de la XII Cumbre ALBA-TCP y conmemoración de su $X$ Aniversario. https://www.albatcp.org/acta/declaracion-final-dela-cumbre-alba-tcp-y-conmemoracion-de-su-x-aniversario/

Alianza Bolivariana para los Pueblos de Nuestra América-Tratado de Comercio de los Pueblos (ALBA-TCP). (2013). Declaración de Guayaquil (Consensuada en el XI Consejo Político del ALBA. https://www.albatcp.org/acta/declaracion-de-guayaquilconsensuada-en-el-xi-consejo-politico-del-alba/

Alianza Bolivariana para los Pueblos de Nuestra América-Tratado de Comercio de los Pueblos (ALBA-TCP). (2012a). Acuerdo para la constitución del Espacio Económico del ALBA-TCP (ECOALBA). https://www.albatcp.org/acta/acuerdo-para-la-constituciondel-espacio-economico-del-alba-tcp-ecoalba/

Alianza Bolivariana para los Pueblos de Nuestra América-Tratado de Comercio de los Pueblos (ALBA-TCP). (2012b). Declaración Conjunta Jefes de Estado y de Gobierno de los países miembros ALBA-TCP VI Cumbre Extraordinaria en la ciudad de Maracay. https://www.albatcp.org/acta/declaracion-conjunta-7/

Alianza Bolivariana para los Pueblos de Nuestra América-Tratado de Comercio de los Pueblos (ALBA-TCP). (2009). Declaración de la VII Cumbre del ALBA-TCP. https://www.albatcp.org/acta/declaracion-conjunta-5/

Alianza Bolivariana para los Pueblos de Nuestra América-Tratado de Comercio de los Pueblos (ALBA-TCP). Acuerdo para la aplicación del ALBA-TCP. https://www.albatcp.org/acta/acuerdo-para-la-aplicacion-del-alba-tcp/

Alpert, H. (1945). Durkheim. Fondo de Cultura Económica. 
Ansaldi, W. (1997). Integración cultural. Una identidad en construcción. Encrucijadas, (6).

Barrios Rodríguez, D. (2019). Guerra híbrida: orígenes y usos políticos. América Latina en movimiento, (544), 9-12. https://geopolitica.iiec.unam.mx/node/597

Bergel, M. (2021). El socialismo cosmopolita de José Carlos Mariátegui. Nueva Sociedad, (293). https://nuso.org/revista/293/pensar-las-desigualdades-en-americalatina/

Boff, L. (2012). El cuidado necesario. Editorial Trotta.

Cardoso, F. H. (1972a). Ideologías de la burguesía industrial en sociedades dependientes. (Argentina y Brasil). Siglo Veintiuno.

Cardoso, F. H. (1972b). Estado y sociedad en América Latina. Nueva Visión.

Castro Leiva, L. (1991). De la patria boba a la teología bolivariana. Monte Ávila.

Chaves Avila, R., y Monzón Campos, J. L. (2003). Economía Social. En A. Ariño Villarroya (Ed.), Diccionario de la solidaridad. Tirant lo Blanch.

Chávez Frías, H., y Castro Ruiz, F. (2004). Declaración Conjunta Venezuela - Cuba (suscripta en la Habana, el 14 de diciembre 2004). https://www.albatcp.org/acta/declaracion-conjunta-venezuela-cuba/

Comisión Económica para América Latina y el Caribe (CEPAL). (2020). La tragedia ambiental de América Latina $y$ el Caribe. Naciones Unidas; CEPAL https://repositorio.cepal.org/handle/11362/46101

Cumbre de América Latina y el Caribe Sobre Integración y Desarrollo (CALC). (2010). Declaración de Cancún. http://s017.sela.org/celac/quienessomos/antecedentes/calc/declaraciones/

Cumbre de América Latina y el Caribe Sobre Integración y Desarrollo (CALC). (2008). Declaración de Salvador, Bahía. http://s017.sela.org/celac/quienessomos/antecedentes/calc/declaraciones/

Comunidad Andina de Naciones (1968). Acuerdo de Integración Subregional Andino (Acuerdo de Cartagena) https://bibliotecaparlamentoandino.janium.net/janium/Referen/Acuerdo-de-Cartagena.pdf

Cumbre de la Comunidad de Estados Latinoamericanos y Caribeños (CELAC). (2011). Declaración de Caracas "En el Bicentenario de la Lucha por la Independencia Hacia el Camino de Nuestros Libertadores". https://www.cancilleria.gob.bo/celac/sites/default/files/201902/Declaracion de Caracas.pdf

Da Motta Veiga, P., y Halperin, M. (2001, 26 de marzo). Definición de una estrategia para la preservación de las preferencias intra-ALADI en el acuerdo que establecería el ALCA (Estudio ALADI/SEC/132). Asociación Latinoamericana de Integración. 
http://www2.aladi.org/nsfaladi/estudios.nsf/vpublianterioreswebp/8D91E3BB75A11D37 03256A2500678EDF

Da Motta Veiga, P., y Halperin, M. (2001, 13 y 14 de agosto). Impacto del ALCA en la economía del Paraguay $y$ en sus negociaciones en la ALADI. Asociación Latinoamericana de Integración; Ministerio de Relaciones Exteriores del Paraguay. http://www2.aladi.org/nsfaladi/estudios.nsf/vwmateriasestudiosweb/BA3137D01F1E8D 2103256AA40071E53B

Da Motta Veiga, P., y Halperin, M. (2001, 27 al 30 de agosto). Impacto del ALCA en la Economía del Ecuador y sus negociaciones en la ALADI. Asociación Latinoamericana de Integración; Ministerio de Relaciones Exteriores del Ecuador. http://www2.aladi.org/nsfaladi/estudios.nsf/vpublianterioreswebi/BAD485FA1E0E260B 03256AB00050CBD7

De Valera, C., y De Reina, C. (1927). La santa biblia que contiene los sagrados libros del antiguo y nuevo testamento. Antigua versión de Cipriano De Valera. Sociedad bíblica británica y extranjera de Londres.

Durkheim, E. (1967). De la división del trabajo social. Editorial Schapire.

EcuRed. (s/f). OEA. www.ecured.cu/OEA.

Freyer, H. (1944). La sociología ciencia de la realidad. Losada.

Freyer, H. (1945). Introducción a la sociología. Nueva Época.

Funes, P. (2011). Intervención en el panel "Nuevos procesos latinoamericanos" en las IX Jornadas de la Carrera de Sociología de la Universidad de Buenos Aires 8 a 12 de agosto. Densidades, (7), 137-149. https://issuu.com/densidades/docs/densidades n 7

Giacalone, R. (2021, abril). Venezuela en MERCOSUR: aproximación a un balance de sus consecuencias regionales. Informe Integrar, (127), 31-43. https://www.iil.jursoc.unlp.edu.ar/sitio/index.php/site-administrator/boletin

Gudynas, E. (2016, 11 y 12 de Julio). Los derechos de la naturaleza ante los extractivismos sudamericanos. Curso: Los derechos de la naturaleza y los extractivismos. FLACSO, Quito y Centro Latinoamericano de Ecología Social. http://extractivismo.com/2016/07/derechos-de-la-naturaleza-y-extractivismossudamericanos/

Grupo de Puebla (2021). Manifiesto Progresista del Grupo de Puebla. https://www.grupodepuebla.org/manifiestoprogresista/

Grupo de Puebla (2019). Declaración de Puebla. https://www.grupodepuebla.org/declaracion-de-puebla/

Halperin, M. (2020). La ciudadanía digital en el cielo latinoamericano. Informe Integrar, (124), 2-15. https://www.iil.jursoc.unlp.edu.ar/sitio/index.php/site-administrator/boletin 
Halperin, M. (2021). Los tratados de libre comercio de última generación y su incidencia sobre la competitividad relativa de países en desarrollo. Informe Integrar, (129), 2-34. https://www.iil.jursoc.unlp.edu.ar/sitio/index.php/site-administrator/boletin

Ianni, O. (1973). Populismo y relaciones de clase. En O. lanni, G. Germani, y T. Di Tella, Populismo y contradicciones de clase en Latinoamérica. Editorial Era.

Kojève, A. (1982). La dialéctica del amo y el esclavo en Hegel. La Pléyade.

Lamo de Espinosa, E., y Llobera, J. R. (1995). Culturas, Estados y ciudadanos. Una aproximación al multiculturalismo en Europa. Alianza.

Lyotard, J. F. (1991, junio). La condición postmoderna. Informe sobre el saber (2da. Edic.). Editorial R.E.I.

Mariátegui, J. C. (2021). Antología. Selección, introducción y notas de Martín Bergel. Siglo XXI.

Ministerio de producción, comercio exterior, inversiones y pesca de Ecuador. (2021). Libro Blanco de Economía Circular de Ecuador. https://www.produccion.gob.ec/libroblanco-de-economia-circular-de-ecuador/

Ministerio de relaciones exteriores de Bolivia. (2018). Bases de la filosofía del vivir bien. https://www.cancilleria.gob.bo/webmre/node/1231

Ministerio de relaciones exteriores de Uruguay. (2020). Comunicado de Prensa 18/2020. $\quad$ https://www.gub.uy/ministerio-relacionesexteriores/comunicacion/comunicados/1820-cancilleria-anuncia-retiro-del-uruguayunasur-su-regreso-tiar

Pasquaré, A. (2014, 5, 6 y 7 de noviembre). Exilio y patria en Manuel Ugarte: su campaña continental de 1911-1916. II Jornadas de trabajo sobre exilios políticos del cono Sur en el siglo XX, Montevideo, Uruguay. https://memoria.fahce.unlp.edu.ar/trab eventos/ev.4002/ev.4002.pdf

J. J. Paz, y Miño Cepeda, J. (2016, Julio). El nuevo rol de la OEA: ¿el regreso del americanismo? Nueva Sociedad Opinion. https://nuso.org/articulo/el-nuevo-rol-de-laoea-regreso-del-americanismo/

Philip, G. (2017). Contrapunteo entre la perspectiva histórica transcultural de Fernando Ortiz y la corriente antropológica culturalista norteamericana de Franz Boas. REA, (23), 175-189. http://hdl.handle.net/2133/12391

Podetti, J. R. (2015). Cultura y alteridad. En torno al sentido de la experiencia latinoamericana. Ciccus.

Romero Alfonzo, A. J. (2021). Simón Rodríguez: precursor de la economía social en América Latina. En J. L. Coraggio (Ed.), Miradas sobre la economía social y solidaria en América Latina (pp. 197-244). Universidad Nacional de General Sarmiento; CLACSO.https://ediciones.ungs.edu.ar/wp-content/uploads/2017/10/9789876302913completo.pdf / 
Schaposnik, C. R., y Pardo, E. C. (2016). Venezuela: giros en la integración regional y señales de cambio en su estructura productiva. En N. B. Mellado (Dir. y Ed.), Latinoamérica: inserción global e integración regional (pp. 177-200). Ediciones Lerner. http://sedici.unlp.edu.ar/handle/10915/59807

Schmelzer, M. (2007). Comercio justo y libre mercado. Universidad de California. www.academia.edu

Sercovich, F. C. (1974). Dependencia tecnológica en la industria argentina. Desarrollo Económico. Revista de Ciencias Sociales, 14(53), 33-67.

Soler, R. (1980). Idea y cuestión nacional latinoamericanas. Siglo Veintiuno Editores.

Unión de Naciones Suramericanas (UNASUR). (2008). Tratado Constitutivo de la Unión de Naciones Suramericanas. http://www.iirsa.org/admin iirsa web/Uploads/Documents/rp brasilia08 cumbre unas ur tratado constitutivo.pdf

Vierkandt, A. (1934). Filosofía de la sociedad y de la historia. Biblioteca de la Universidad Nacional de La Plata.

World Trade Organization. (2020, April 23). Export prohibitions and restrictions. Information note. https://www.wto.org/english/news e/news20 e/rese 23 apr20 e.htm

Zhuang, W. (2016). Hacia un acuerdo comercial para regular los incentivos a las energías renovables. Puentes, 17(6).

HALPERIN, MARCELO: Abogado, Universidad Nacional de Buenos Aires. Egresado de la Escuela de Sociología. Doctor en Derecho y Ciencias Sociales por la Universidad Nacional de Córdoba, Argentina. Consultor de organismos internacionales de integración y cooperación económica. Investigador y docente del Instituto de Integración Latinoamericana de la Universidad Nacional de La Plata.

Fecha de recepción: 21-09-2021

Fecha de aceptación: 17-11-2021 